\title{
New Support Roller Profile Design for Railway Wheel Re-profiling Process by Under-floor Lathes With a Single Cutting Tool
}

Eduardo Corral ( $\nabla$ ecorral@ing.uc3m.es )

UC3M: Universidad Carlos III de Madrid https://orcid.org/0000-0003-1636-6093

Jesús Meneses

UC3M: Universidad Carlos III de Madrid

M.J. Gómez García

UC3M: Universidad Carlos III de Madrid

Cristina Castejón

UC3M: Universidad Carlos III de Madrid

Juan Carlos García-Prada

UC3M: Universidad Carlos III de Madrid

\section{Research Article}

Keywords: profile design, railway wheel, re-profiling, under-floor lathes, Design engineering

Posted Date: June 3rd, 2021

DOl: https://doi.org/10.21203/rs.3.rs-519543/v1

License: (9) This work is licensed under a Creative Commons Attribution 4.0 International License. Read Full License

Version of Record: A version of this preprint was published at Scientific Reports on January 7th, 2022.

See the published version at https://doi.org/10.1038/s41598-021-04190-y. 


\title{
New support roller profile design for railway wheel re-profiling process by under-floor lathes with a single cutting tool
}

\author{
* Eduardo Corral 0000-0003-1636-6093; Jesús Meneses; M.J. Gómez García 0000-0001- \\ 9922-2313, Cristina Castejón, Juan Carlos García-Prada \\ MaqLab research group, Universidad Carlos III de Madrid, \\ \{ ecorral, meneses, mjggarci, castejon \}@ing.uc3m.es \\ jcgprada@ind.uned.es
}

\begin{abstract}
The wheel re-profiling is an important part of railway wheelset maintenance.

Researchers and railway operators have been very concerned about how to minimize the loss of time during wheel re-profiling without decreasing safety. Avoiding wheelset disassembly means considerable time savings, while reducing wheel damage during operation. Underfloor wheel lathes are the most appropriate tool to achieve this double objective, and therefore the most used nowadays.

Multi-cut tool lathes have the disadvantage of being extremely expensive. On the other hand, with single tool lathes, re-profiling is not smooth or safe enough when current convex profile support rollers are used.

In this article, a methodology to optimize the profile of the support rollers used in underfloor single tool lathes for railway wheel re-profiling is proposed. This novel profile design will minimize damage and increase the safety of such lathes, since it proposes a greater smoothness in the process. Simulations of re-profiling process have been carried out by the finite element method showing that the designed roller profile reduces drastically the impact/damage during the operation.
\end{abstract}

Profile-optimized support rollers have been used in a real underfloor wheel lathe, showing good results.

Keywords: profile design, railway wheel, re-profiling, under-floor lathes, Design engineering

\section{Introduction}

Improving the safety and security of transport has been a major objective in the last decades. Especially, the railway industry requires careful consideration for the problems related to the contact between wheel and rail.

Predictive maintenance and inspections of each rolling element of the wheelset have become vitally important. Non-traditional techniques that have been developed for general rotating machinery are starting to be applied for wheelsets condition monitoring [1]. The rolling elements are the most critical due to vibrations [ 2][3] 
Wheels are the most important moving parts of a train that have a crucial impact on driving safety. Due to the spreading and complexity of the contact force between the wheelset and the rails, the wheel tread and flange may lose their original shape due to the damage after certain kilometers of travel.

This wheel wear causes many inconveniences, including the famous "railway wheel flats". Railway wheel flats are induced by unintentional sliding between the wheel and rail at breaking [4][5]. The impact load caused by wheel flats, depends on the depth and length of flats, as well as on the train speed and load. This impact load can be several times higher than the wheel static load [ 6][ 7][ 8][ 9]. Wheel flats are the main causes of wheel bearing damage, axle temperature rise, axle fracture, as well as rail and concrete sleeper fracture [10][ 11]

The wheel wear immediately affects the quality of the train's operation (stability, safety and passenger comfort) and the life of the rails [12][13][ 14]

For these reasons, the wheels have to be re-profiled to restore its geometry tread for purpose of maintenance. The re-profiling process is considered an important part of the maintenance of trains in service, both corrective maintenance (keeping the safety limits according to standards; removing the wheel defects and wear) and conditional maintenance (optimization the re-profiling interval determined by research; removing wheel defects at the beginning; minimization of the components stress; noise reduction; improve the wheel time life)

Nowadays, every year tens of millions of railway wheel are re-profiled.

The profiling and re-profiling is a subject of current research with several methods, like the roller burnishing[15]. These methods are being optimized more and more[16]. These methods are complex and depend on many factors, such as the position of the cutting tool[ 17], of the verification of its curvature [18], or the importance of the surface quality [19]. Hoon Hun applied an optimization of a roller levelling with finite element analysis [20]. Yanglin Peng developed a method to control the tool deflection error [ 21

Currently, the re-profiling process is commonly carried out by turning and mold-milling. For example, the Danobat under wheel lathe (see Image 1) is a specific machine tool for the corrective maintenance of railway rolling surfaces. It can perform the re-profiling without the need for dismounting the train axle and is equipped with the latest technology. The Stanray TM Underfloor Wheel Truing Machine (TN-84C) [ 22] is an underfloor pit-mounted milling machine capable of simultaneously re-profiling both wheels of a railway wheel set using the axle centers as the machining reference point.

At the moment, there are not many studies on re-profiling in the literature. Some scholars carried out studies on wheel re-profiling strategy and profile optimization design; Zhang et al. proposed a multiobjective optimized re-profiling model that helped to reduce re-profiling quantity and made it possible for wheels with abrasion loss to attain comprehensive performance of master profile thereby extending their service life [23]. Chien et al. studied wheel wear statistical data processing method based on mathematical statistics and built a wheel re-profiling period prediction model [24]. With respect to wheel tread re-profiling process, many scholars have carried out research. Seo et al. studied effects of metal removal and residual stress on the contact fatigue life of railway wheels by applying 
finite element analyses and conducting corresponding fatigue test. [25]. Resilient wheels are made to reduce noise and improve comfort of travelling with lightweight railways. This solution may be a problem during turning of such wheelset on axle turning lathes. The biggest problem in turning resilient wheelsets on wheel-turning lathes with friction drive appears to be axial deformation of wheel during the machining process. Filipowicz et al. used a FEM model to check if turning of resilient wheelsets on friction drive lathe is possible. The results showed that although cutting forces are very high, values of radial displacement are not big, and they do not have influence on geometry of machined type, especially while turning [26]. There are many different types of milling cutters for wheel tread re-profiling. Sometimes choosing a reasonable milling cutter to reduce processing costs at wheel tread re-profiling is quite difficult. Based on the experimental research, Tian analyzed the difference of the total using cost of different milling cutters and provided the theoretical basis for the economic selection of milling cutters [27]. Cioboata et al. presented some considerations on the development of a technological system for profiling/re-profiling and measurement of the profile of the railway wheel sets in order to improve maintenance of railway transport [28]. Andrade and Stow assessed the technical efficiency of different operators turning railway wheelsets on an underfloor wheel lathe, using a stochastic frontier analysis, and taking into account other explaining variables such as the flange thickness and the occurrence of rolling contact fatigue defects, wheel flats, and cavities[29]

In summary, researchers have so far made a great deal of research and got lots of achievements regarding wheel profile optimization, machined surface, cutting heat and cutting force, and so forth during metal cutting. However, after extensive consultation, the authors have not found literature on the optimal shape of the support rollers used in underfloor lathes for railway wheel re-profiling.

Locomotive researchers and railway operators should always bear in mind the way to reduce residual stress at wheel tread, surface roughness and wheel damage during wheel tread re-profiling and avoid impacts, thereby extending the life cycle of wheelsets and minimizing the wheelset maintenance cost.

This paper proposes a method to find the optimal shape of the support rollers of a single tool underfloor wheel lathe, to avoid sudden load transfers during the process. The new shape of the roller profile has been analyzed through the dynamic simulation analysis of the wheel re-profiling process by means of a finite element method.
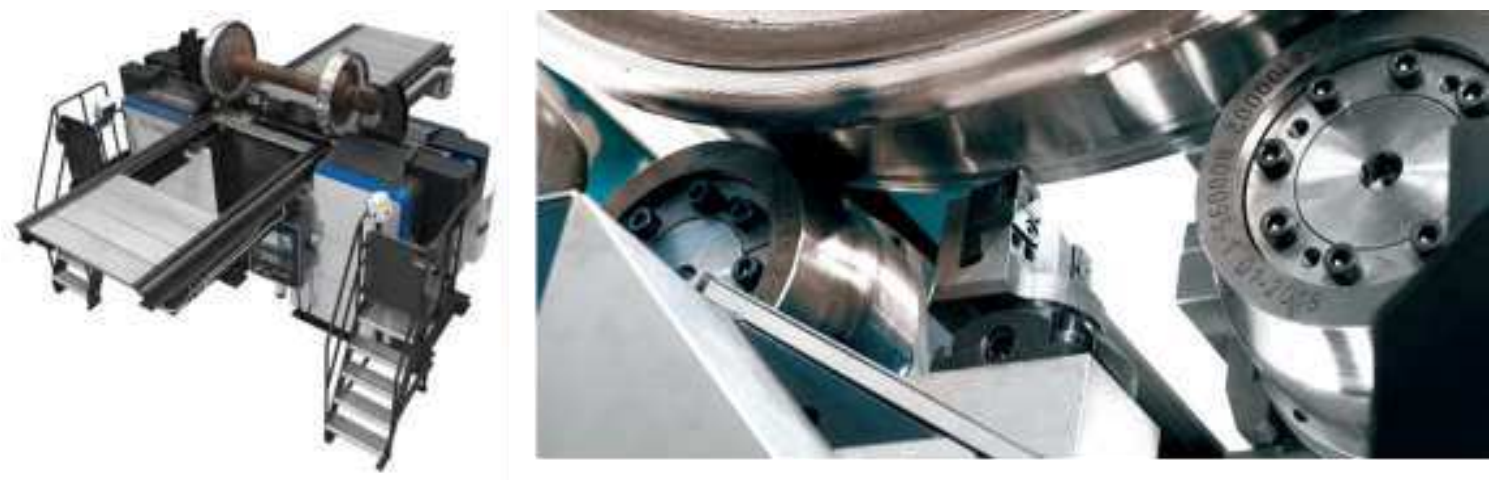

Figure 1. Single tool underfloor wheel lathe for railway wheel re-profiling 


\section{Description of the problem associated with a single tool under- floor lathe for railway wheel re-profiling}

In this section, the problem associated with a single tool underfloor lathe equipped with support rollers (two rollers for each wheel, at least one of them motorized) is described.

The cutting tool works in a vertical plane between both rollers (see Figure 2)

Nowadays in this kind of lathes, support rollers are used whose profile is an arc of circumference, so they are totally convex. To illustrate the problems associated with these roller profiles, in Figure 3 several phases of the re-profiling process of a wheel (in blue), of conicity semi-angle $-\beta$, supported on a generic profile roller (in red) are presented. The slope of the roller profile will be negative in the area of the roller that we will call "useful" (AC section), of width $a$.

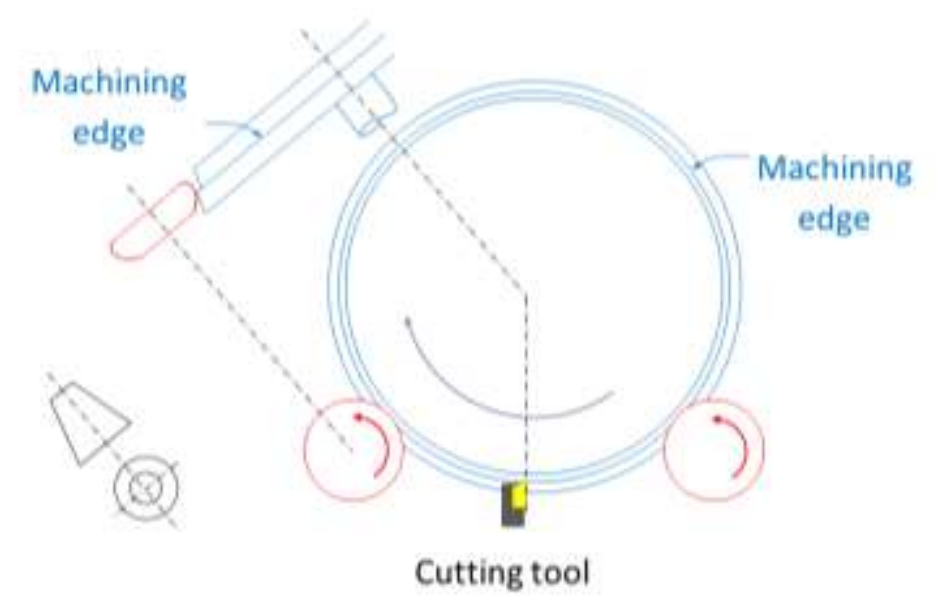

Figure 2. Front and side views showing the configuration of the support rollers (red), the cutting tool (yellow) and the wheel to be re-profiled (blue). The machining edge during the re-profiling process is also shown

At the beginning, the wheel rests on the roller at point A, where the wheel slope and the roller slope are both equal to $\beta$ (Figure 3a). This point will be the support point until it is reached by the machining edge (Figure $3 \mathrm{~b}$ ). From then on, the support will take place on the machining edge (point $\mathrm{P}$ ), which runs along the profile of the roller (Figure 3c). Meanwhile, the already re-profiled surface will approach the point of the first roller support, point $\mathrm{A}$. When the machining edge reaches point $\mathrm{B}$, a support transfer occurs (Figure 3d), at the end of which, the wheel will be supported again on point A, on its already re-profiled area (Figure $3 \mathrm{e}$ ).

Throughout the re-profiling process, the contact force between the roller and the wheel changes in its direction and in its distribution over the contact area(s). In fact, a load transfer from contact on point B to contact on point A occurs in phase d) (Figure 3). This load transfer supposes an abrupt decrease in its axial component, and usually causes undesirable impact and stability problems, so it is worth studying it in depth. If we consider the roller and wheel as rigid solids, the load transfer between B and A would be instantaneous; but if they are considered as deformable bodies, the contact surface at B will decrease while the contact surface in A will increase, resulting in a less abrupt load transfer.

The new design of the roller profile is first optimized considering the roller and the wheel as rigid solids. Once the optimal profile is proposed, the process will be studied considering both as deformable solids. For this purpose the finite element technique will be used. 

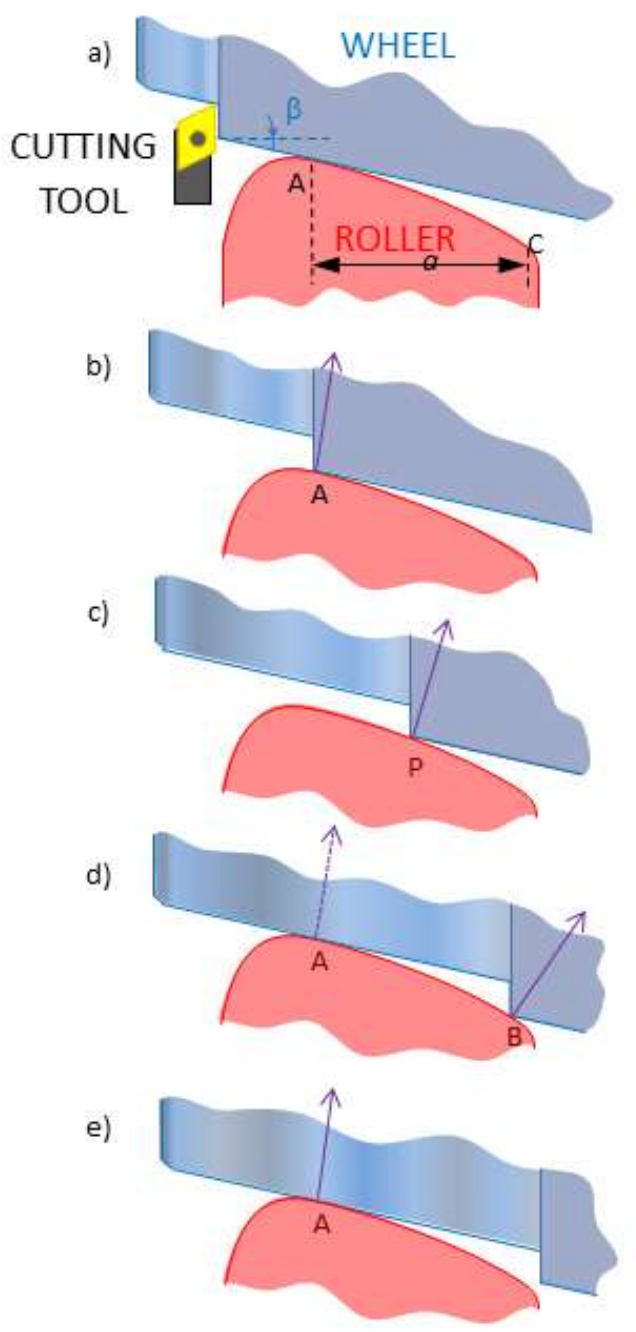

Figure 2. Cross section of roller and wheel at different re-profiling phases (the cutting tool drawn in a) is out of section)

\section{Roller profile design}

In the intermediate phase of the re-profiling process, when the roller-wheel contact occurs on the machining edge, point $P$ (figure 1c), the already re-profiled surface of the wheel approaches towards point $\mathrm{A}$ of the roller, where it will eventually be supported again.

In Figure 4 two moments of the re-profiling process separated by a small time interval, $\Delta t$ (in blue and purple, respectively) have been represented. $V_{a}$ and $V_{m}$ are the approach and machining speeds respectively, $s$ is the distance between contact points at $t$ and $t+\Delta t$. It can be seen that the greater the difference between the inclination of the wheel, $\beta$ and the slope of the roller profile in the contact, $\gamma$, the greater the speed with which the re-profiled surface approaches to point A. 
a)

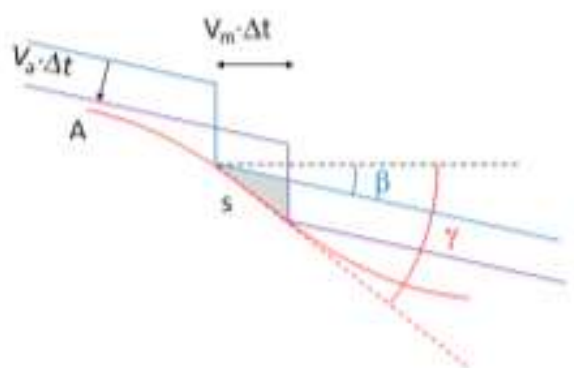

b)

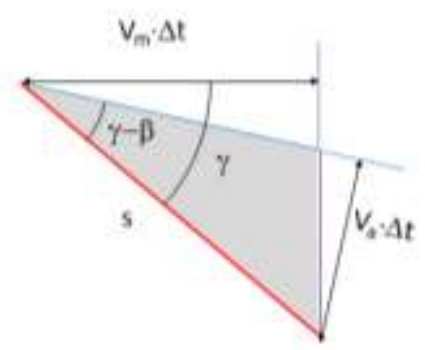

Figure 3 a) Two succesive positions (separated by the time Interval $\Delta t$ ) of the wheel being re-profiling (in blue and purple, respectively) supported on the roller (in red). b) detail of the shaded area showing the involved velocities (machining velocity, $\mathrm{V}_{\mathrm{m}}$; and approach velocity, $\mathrm{V}_{\mathrm{a}}$ ) and angles (slope of the wheel, $\beta$; and that of the roller profile at the contact, $\gamma$ ).

In fact, from Figure 4 we have:

$$
\mathrm{V}_{\mathrm{a}}=\mathrm{V}_{\mathrm{m}} \frac{\sin (\gamma-\beta)}{\cos \gamma}
$$

In rollers whose useful profile is totally convex, as those used at present, the slope of the roller is a monotonous diminishing function, reason why it goes away of the value of the inclination of the wheel as the machining edge moves away from point A. Therefore, the approach speed increases as the re-profiling process progresses, and can become considerably high at the time just before the double support (phase $d$ in Figure 3), producing a more abrupt load transfer than desired.

Note that for rollers with a totally convex profile, the load transfer between points A and B is accompanied by a discontinuity in the axial component of the roller-wheel contact force: in $\mathrm{B}$ it is much larger than in A (see Figure 3)

For the load transfer to be smooth enough, the slope of the roller profile at point B should be only slightly higher than the wheel inclination (which coincides with the slope of the roller at point A, the flank of the wheel considered linear). Thus, the curve proposed as the roller useful profile has an inflection point, where it becomes from convex to concave. The designed profile must also ensure that the second support is made actually at point $\mathrm{A}$, before:

i) the machining edge leaves the useful area of the profile, and

ii) the support is produced at a point other than A, on a not yet re-profiled area (undesirable support).

These two undesirable circumstances, represented in Figure 5, would both imply impulsive support at point $\mathrm{A}$.
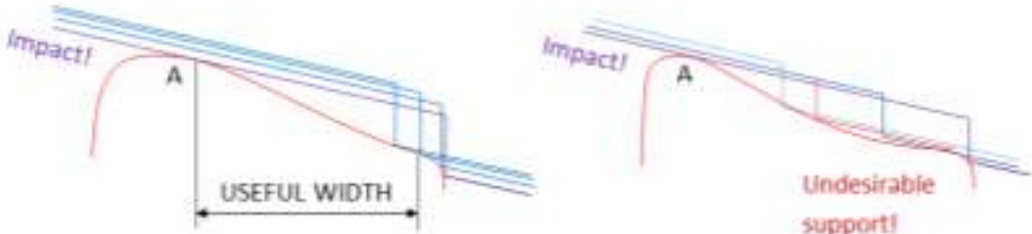

Figure 5. Situations that lead to a second impulsive support of the wheel in the re-profiling process: i) the re-profiling edge leaves the area of useful width prematurely (left); ii) there is prior undesirable support (right). 
In particular, the profile of the roller will be described by its radius $r(x)$, as a function of the axial distance $x$. The slope of this function should be $\beta$ at the ends of the useful width. The parameters to consider in the profile design are: the roller radius $R$ at point $\mathrm{A}$, the useful width $a$, the machining depth $e$, and the slope of the wheel to be re-profiled $\beta$. As a design requirement, a safety section of length $s$, must also be contemplated to guarantee a desirable support before circumstance $\mathrm{i}$ ). This length should not be too large, so that the slope of the roller at the point B (machining edge position at the double support phase), is only slightly greater than that of the wheel. Therefore, the following constraints must be met for $r(x)$ (see Figure 5):

C1) $r(0)=R$, roller radius.

C2) $r^{\prime}(0)=r^{\prime}(a)=-\tan \beta$

C3) The load transfer occurs when the machining edge is located at point B, at the safety section $s$, from the last point of the useful area, C.

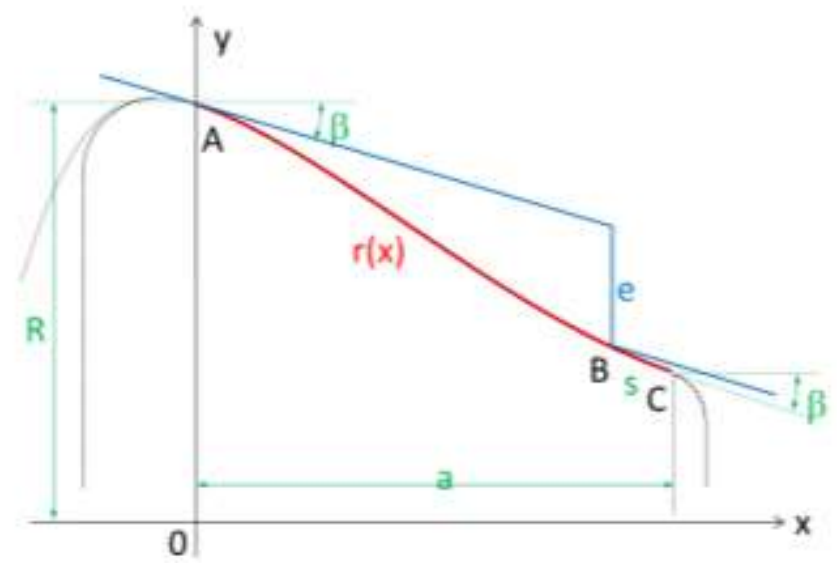

Figure 6. Roller profile according to constraints. Wheel profile in the double support phase of the re-profiling process. Design parameters: $\beta, \mathrm{a}, \mathrm{R}, \mathrm{e}, \mathrm{s}$

Limitations i), ii) and constraint C2) impose an essential geometrical feature to the profile of the roller: it must be composed of a convex section followed by a concave section; therefore, it should have an inflection point in the useful area. The simplest and easiest-to-manufacture roller profile is one composed of two tangent circumference arcs. Below is the calculation process to obtain the optimal profile of this type of roller.

Optimal roller profile calculation involves the resolution of a nonlinear system of equations. For that reason, the proposed profile has been calculated in two steps. In the first one, no safety section is considered, which leads to a system of equations that can be solved exactly; the corresponding results are utilized in the second step, as the initial guess for the Newton-Raphson's iterative method.

\subsection{First step: profile calculation without considering safety section}

The Figure 7 shows the roller profile composed of two circumference sections, one convex and one concave, having an inflection point between them. The position of the wheel profile is also shown at the moment of re-profiling process in which double support occurs. As can be seen, at that moment the machining edge reaches exactly the right useful limit of the roller profile, no safety section being considered.

In this first approach, the design parameters are: the wheel slope, $\beta$; the useful area length of the roller, $a$; the machining depth, $e$; and the roller radius, $R$ (corresponding to the first and last rollerwheel contact points). Whereas the design variables are the radius of arc sections, $R_{1}$ and $R_{2}$ and the 
position coordinates for the corresponding centres $\left(\mathrm{X}_{1}, \mathrm{Y}_{1}\right)$ and $\left(\mathrm{X}_{2}, \mathrm{Y}_{2}\right)$. These variables must fulfil the following system of equations (see Figure 7):

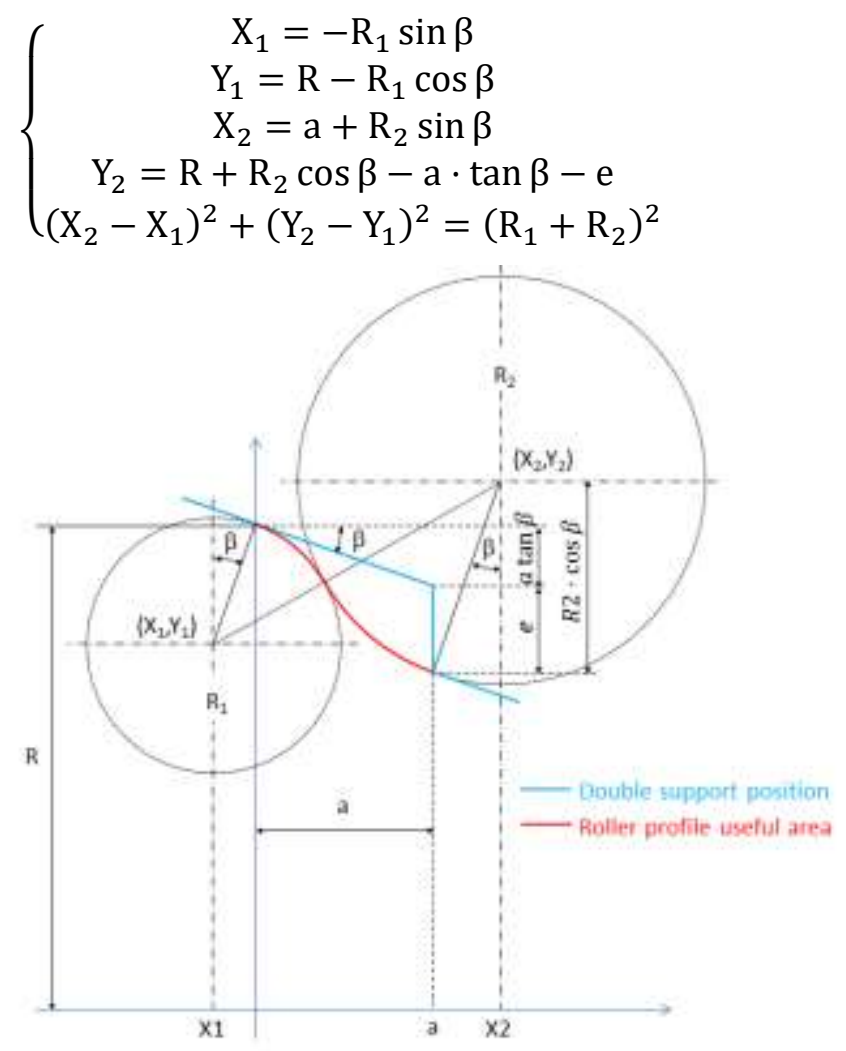

Figure 7. Roller profile composed of two circumference sections. Positions of the circumference centres and radios. First approach design without considering safety distance.

There are 5 equations for 6 variables, so just one variable is independent. The radius of one of the arc sections $\left(R_{1}\right.$, for example) can be taken as the independent variable, the rest of variables being expressed as function of $R_{1}$. The system is not linear but it can be solved exactly. Actually, replacing the first 4 equations in the last one and operating, we get:

$$
\mathrm{R}_{2}=\frac{\mathrm{a}^{2}+(\mathrm{a} \cdot \tan \beta+\mathrm{e})^{2}}{2 \mathrm{e}}-\mathrm{R}_{1}
$$

The value for the rest of the variables is then obtained immediately.

If the profile is required to have one convex section followed by a concave one (as in Figure 7), the value chosen for $R_{1}$ cannot be arbitrarily large, since the sum of radii $R_{1}+R_{2}$ has a fixed value for a set of parameters $\beta, a, e$. This implies the following limit for $R_{1}$ :

$$
\mathrm{R}_{1}<\frac{\mathrm{a}^{2}+(\mathrm{a} \cdot \tan \beta+\mathrm{e})^{2}}{2 \mathrm{e}}
$$

Otherwise, the value of $R_{2}$ would be negative and the useful profile area would no longer have a concave section. Of course, a negative value of $R_{1}$ implies that the entire useful profile is concave.

In theory, it is desirable a large value of the concave arc section, so that the double support occurs more smoothly. However, the convex arc section should be sufficiently large to ensure a sturdy and stable support, since the wheel will rest on that area during most of the re-profiling process. Furthermore, the smaller the radius of a section, the greater the variation of the axial component of the roller-wheel force during the passage of the machining edge through that section. 


\subsection{Second step: profile calculation considering safety section}

When the safety section length $s$, measured along the concave section (magenta arc in Figure 8), is considered as a design parameter, the system of equations becomes:

$$
\left\{\begin{array}{c}
\mathrm{X}_{1}+\mathrm{R}_{1} \sin \beta=0 \\
\mathrm{Y}_{1}+\mathrm{R}_{1} \cos \beta-\mathrm{R}=0 \\
\mathrm{X}_{2}-\mathrm{R}_{2} \sin \beta-\mathrm{a}=0 \\
\mathrm{Y}_{2}+\mathrm{R}_{2}\left\{\left[\sin \beta-\sin \left(\beta+\frac{\mathrm{s}}{\mathrm{R}_{2}}\right)\right] \tan \beta-\cos \left(\beta+\frac{\mathrm{s}}{\mathrm{R}_{2}}\right)\right\}+\mathrm{e}+\mathrm{a} \cdot \tan \beta-\mathrm{R}=0 \\
\left(\mathrm{X}_{2}-\mathrm{X}_{1}\right)^{2}+\left(\mathrm{Y}_{2}-\mathrm{Y}_{1}\right)^{2}-\left(\mathrm{R}_{1}+\mathrm{R}_{2}\right)^{2}=0
\end{array}\right.
$$

Now, for a given value of $\mathrm{R}_{1}$, the first two equations (which are identical to those corresponding to the system of equations 2 ) directly provide the position of the centre of the convex $\operatorname{arc}\left(\mathrm{X}_{1}, \mathrm{Y}_{1}\right)$. To obtain the radius of the concave arc, $\mathrm{R}_{2}$, and the position of its centre, a non-linear system of three equations (the last three equations 5) must be solved. The unknown vector $\mathbf{q}$, and the constraint vector $\phi(\mathbf{q})$ for this system are respectively:

$$
\begin{aligned}
& \mathbf{q}=\left(\begin{array}{l}
\mathrm{x}_{2} \\
\mathrm{y}_{2} \\
\mathrm{R}_{2}
\end{array}\right)
\end{aligned}
$$

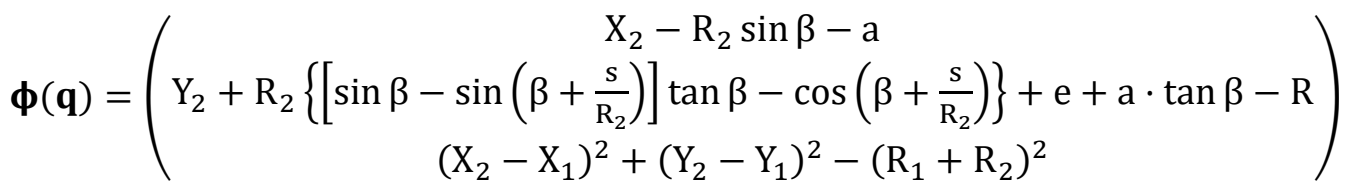

The system will be solved numerically, applying the Newton-Raphson iterative method:

$$
\mathbf{q}^{(\mathrm{j})}=\mathbf{q}^{(\mathrm{j}-1)}-\left[\boldsymbol{\phi}_{\mathbf{q}}\left(\mathbf{q}^{(\mathrm{j}-1)}\right)\right]^{-1} \boldsymbol{\phi}\left(\mathbf{q}^{(\mathrm{j}-1)}\right),
$$

using as the initial guess, the vector obtained with no safety section (equations 2 and 3):

$$
\mathbf{q}^{(0)}=\left(\begin{array}{c}
\mathrm{a}+\left[\frac{\mathrm{a}^{2}+(\mathrm{a} \cdot \tan \beta+e)^{2}}{2 \mathrm{e}}-\mathrm{R}_{1}\right] \sin \beta \\
\mathrm{R}+\left[\frac{\mathrm{a}^{2}+(\mathrm{a} \cdot \tan \beta+\mathrm{e})^{2}}{2 \mathrm{e}}-\mathrm{R}_{1}\right] \cos \beta-\mathrm{a} \cdot \tan \beta-\mathrm{e} \\
\frac{\mathrm{a}^{2}+(\mathrm{a} \cdot \tan \beta+\mathrm{e})^{2}}{2 \mathrm{e}}-\mathrm{R}_{1}
\end{array}\right)
$$

Matrix $\boldsymbol{\phi}_{\mathbf{q}}$ in equation (8) is the jacobian for the constraint equations (7):

$$
\boldsymbol{\phi}_{\mathrm{q}}=\left(\begin{array}{ccc}
1 & 0 & -\sin \beta \\
0 & 1 & \sin \beta \tan \beta+\left[\frac{s}{R_{2}} \cos \left(\beta+\frac{s}{R_{2}}\right)-\sin \left(\beta+\frac{s}{R_{2}}\right)\right] \tan \beta+\frac{s}{R_{2}} \sin \left(\beta+\frac{s}{R_{2}}\right)-\cos \left(\beta+\frac{s}{R_{2}}\right) \\
2\left(\mathrm{X}_{2}-\mathrm{X}_{1}\right) & 2\left(\mathrm{Y}_{2}-\mathrm{Y}_{1}\right) & -2\left(\mathrm{R}_{1}+\mathrm{R}_{2}\right)
\end{array}\right)
$$




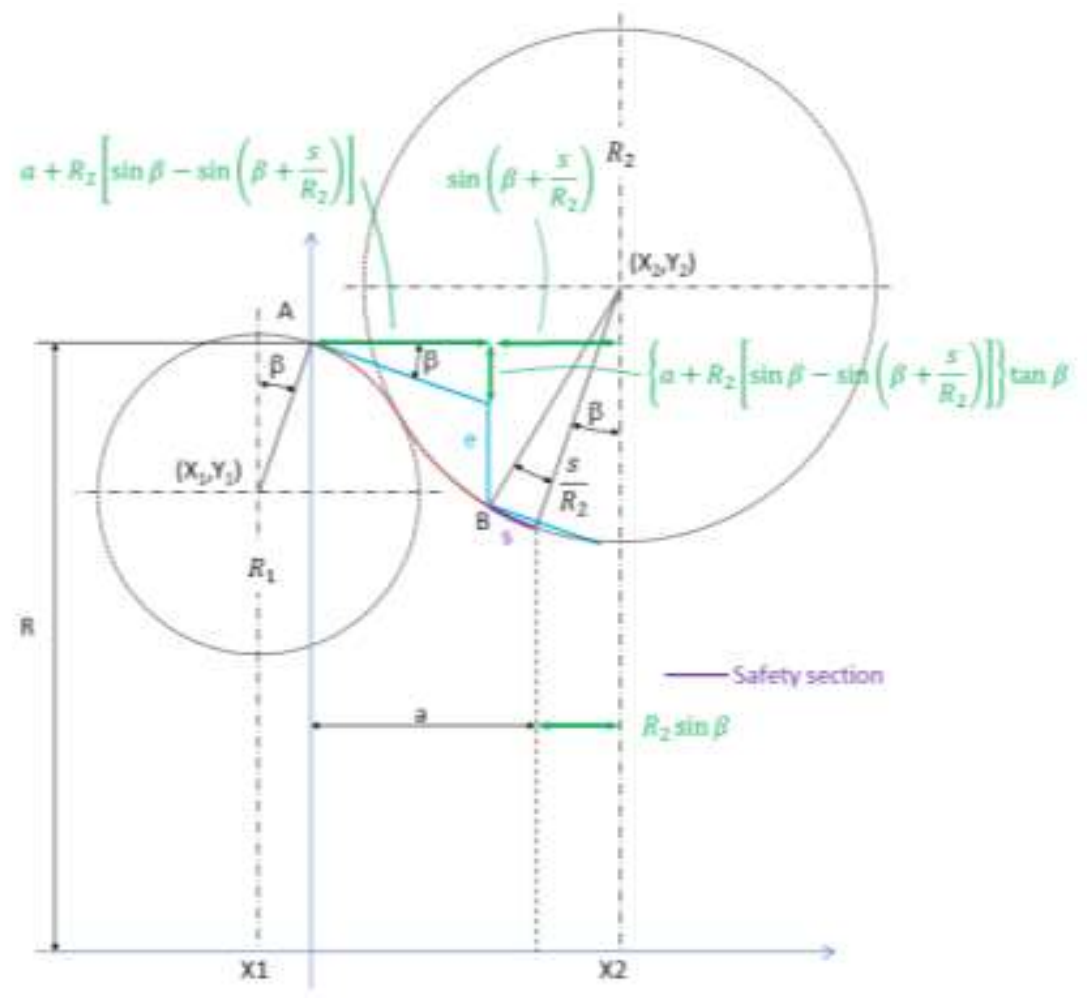

Figure 8. Design parameters of the roller composed of two circumference arcs, considering a safety distance, s.

\subsection{Calculation of the axial force / radial force ratio}

In the re-profiling process, the contact (normal) force between each of the rollers and the wheel can be decomposed into a radial component, and an axial component (see Figure 9). The contact force direction varies as the machining edge runs through the roller profile, so does the axial component to radial component ratio, $\frac{F_{A}}{F_{R}}$, that can be expressed as:

$$
\frac{F_{A}}{F_{R}}=\tan \varphi
$$




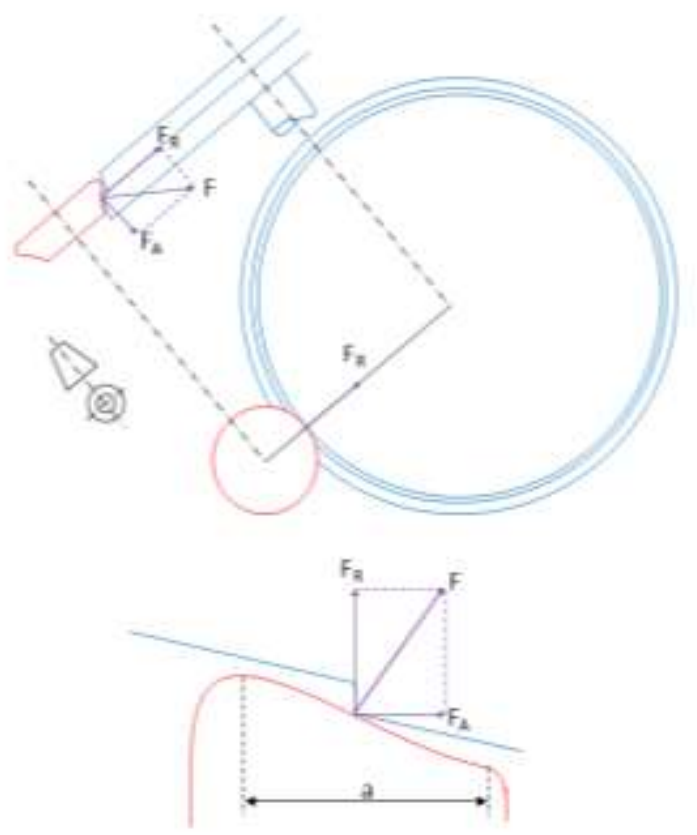

Figure 9. Roller-wheel contact force decomposition into radial and axial components

To express it in terms of the axial position $X$, note the relationship between $X$ and $\varphi$ (that depends on which arc section is in contact with the machining edge. See Figure 10):

$$
X=\left\{\begin{array}{c}
R_{1} \sin \varphi+X_{1} ; 0<X<X_{t} \\
X_{2}-R_{2} \sin \varphi ; X_{t}<X<X_{A}
\end{array} \Rightarrow \sin \varphi=\left\{\begin{array}{c}
\frac{X-X_{1}}{R_{1}} ; 0<X<X_{t} \\
\frac{X_{2}-X}{R_{2}} ; X_{t}<X<X_{A}
\end{array}\right.\right.
$$

So finally, we get:

$$
\frac{F_{A}}{F_{R}}=\tan \varphi=\frac{\sin \varphi}{\sqrt{1-(\sin \varphi)^{2}}}=\left\{\begin{array}{l}
\frac{X-X_{1}}{\sqrt{{R_{1}}^{2}-\left(X-X_{1}\right)^{2}}} ; 0<X<X_{t} \\
\frac{X_{2}-X}{\sqrt{R_{2}{ }^{2}-\left(X_{2}-X\right)^{2}}} ; X_{t}<X<X_{a}
\end{array}\right.
$$




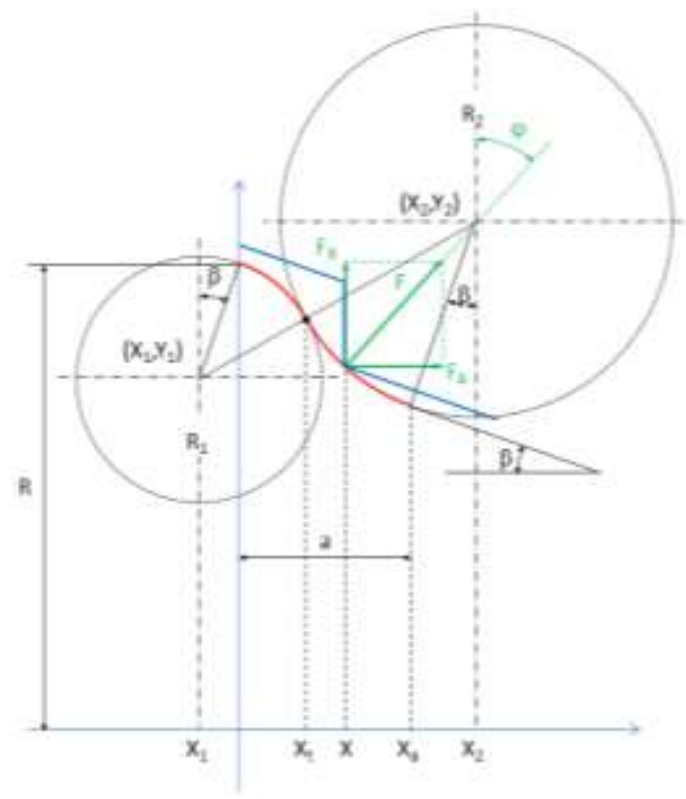

Figure 10. Roller-wheel contact force. Axial and radial components

$\mathrm{A} \mathrm{MATLAB}^{\circledR}$ code has been developed to perform the described iterative calculation and the calculations necessary to obtain the output results: $\mathrm{X}_{1}, \mathrm{Y}_{1}, \mathrm{R}_{2}, \mathrm{X}_{2}, \mathrm{Y}_{2}$ and $\mathrm{F}_{\mathrm{A}} / \mathrm{F}_{\mathrm{R}}$ from the input parameters: $\beta, \mathrm{a}, \mathrm{R}, \mathrm{e}, \mathrm{s}, \mathrm{R}_{1}$. The program also provides the graph of the roller profile together with the wheel profile in the double support position, and that of the roller-wheel contact force axial to radial components ratio. As an example, in Figure 11 these graphics are shown for the following parameters: $\beta=2.86^{\circ}, a=32 \mathrm{~mm}, R=75 \mathrm{~mm}, \mathrm{e}=5 \mathrm{~mm}, \mathrm{~s}=5 \mathrm{~mm}, \mathrm{R}_{1}=30 \mathrm{~mm}$. The output results are also shown.

Note that no practical axial load transfer occurs, as the final $\mathrm{F}_{\mathrm{A}} / \mathrm{F}_{\mathrm{R}}$ value (support at point $\mathrm{B}$ ) practically coincides with the initial one (support at point A). On the contrary, with conventional convex rollers, the $F_{A} / F_{R}$ curve is monotonous increasing up to the point of load transfer, causing an abrupt decrease in the axial load component (see Figure 12). 


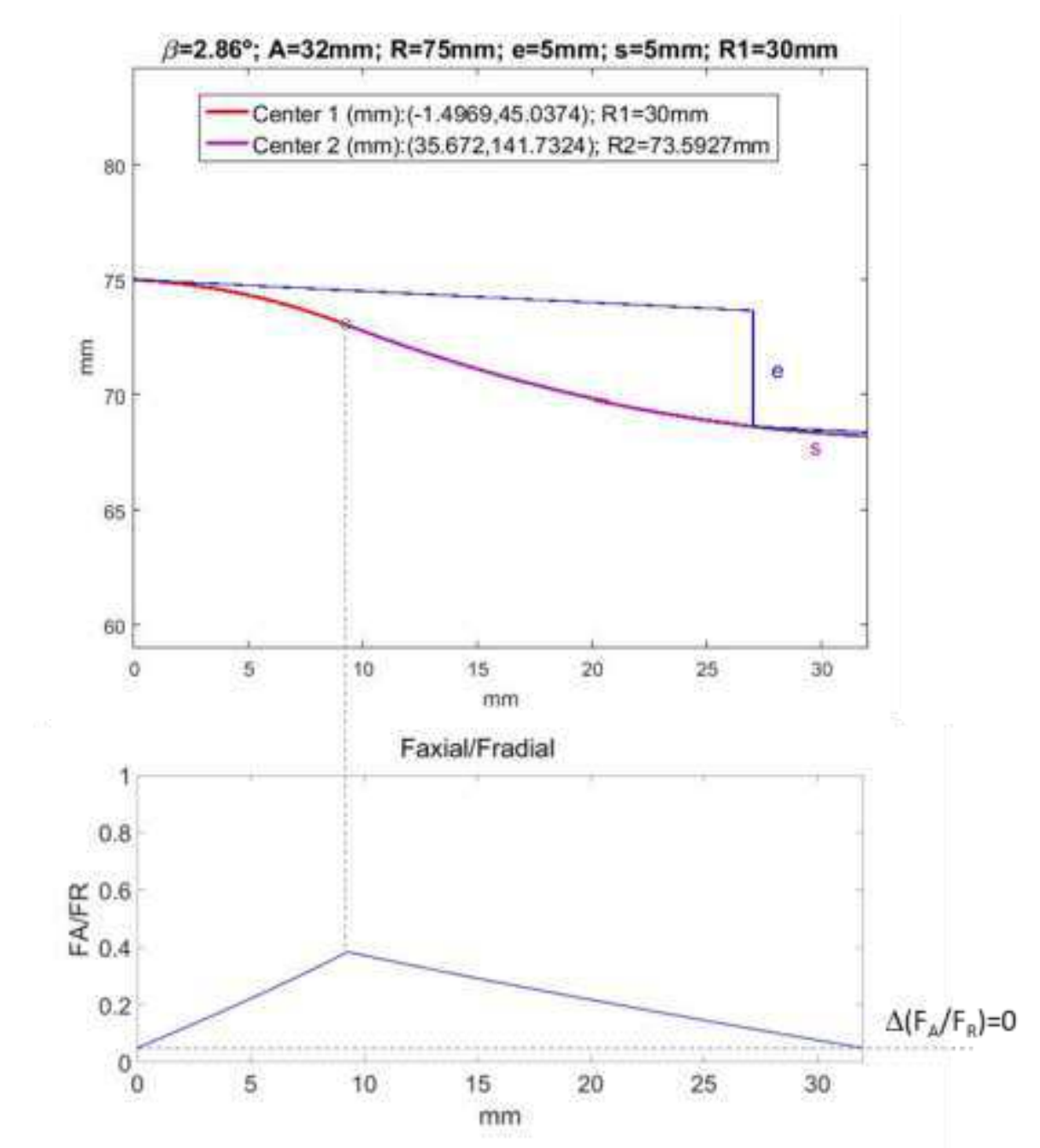

Figure 11. Top: optimal roller profile for the indicated design parameters. Bottom: ratio between the axial and radial components of the contact force, throughout the re-profiling process. the axial component grows to a maximum just at the inflection point of the profile. From that point on, it decreases to the same value as in the first support. As a consequence, there is no axial load transfer. 

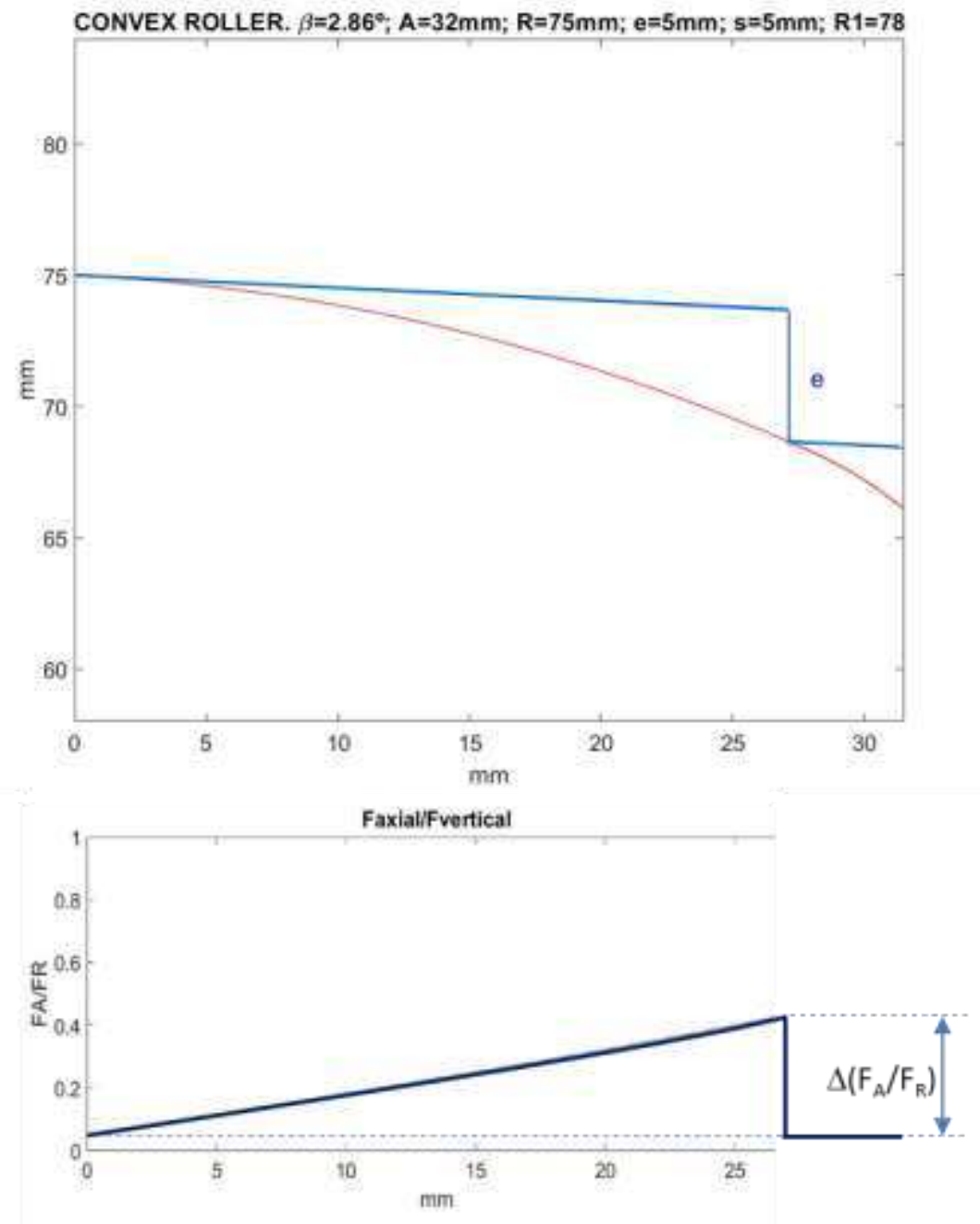

Figure 12. Top: Convex roller profile for the indicated design parameters. Bottom: ratio between the axial and radial components of the contact force, throughout the re-profiling process. In this case, an abrupt load transfer occurs in the second support.

\section{Finite element simulation of the load transfer in the double support phase}

In this section, finite element results for the quasi-static load transfer process (phase $\mathrm{d}$ in Figure 3) are shown. The objective is to provide a criterion for choosing the convex arc radius, $R_{1}$.

To this end, 3 rollers of parameters $\beta=2.86^{\circ}, \mathrm{a}=32 \mathrm{~mm}, \mathrm{e}=5 \mathrm{~mm}, \mathrm{R}=75 \mathrm{~mm}, \mathrm{~s}=4 \mathrm{~mm}$, were simulated for 3 different values of the radius of curvature of the convex arc, $R_{1}=\{10 \mathrm{~mm}, 50 \mathrm{~mm}$, $80 \mathrm{~mm}$. The corresponding profiles are shown in Figure 13, together with the calculated values of the second radius of curvature (concave arc), and the positions of the two centres of curvature, in Cartesian coordinates (x, y). 


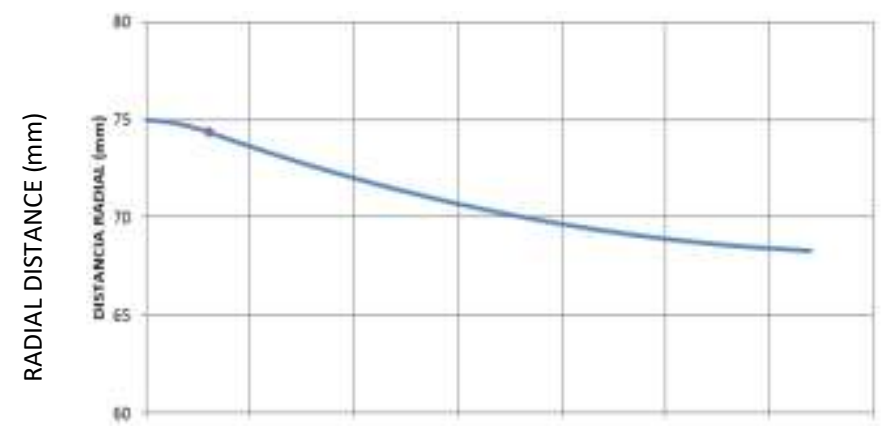

$\mathrm{R}_{1}=10 \mathrm{~mm} ; \mathrm{R}_{2}=95.1 \mathrm{~mm}$

Centre positions $(\mathrm{mm})$ :

$C_{1}=(-0.5,65.0) ; C_{2}=(36.7,163.3)$

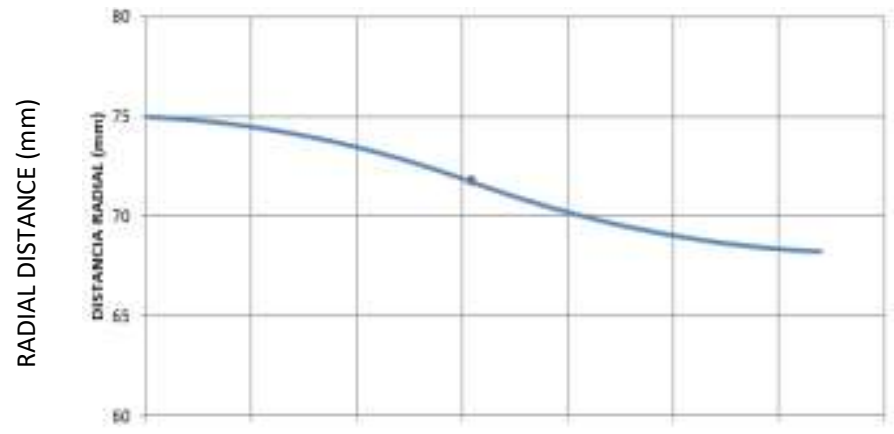

$\mathrm{R}_{1}=50 \mathrm{~mm} ; \mathrm{R}_{2}=53.9 \mathrm{~mm}$

Centre positions $(\mathrm{mm})$ :

$C_{1}=(-2 \cdot 5,25.1) ; C_{2}=(34 \cdot 7,122.1)$

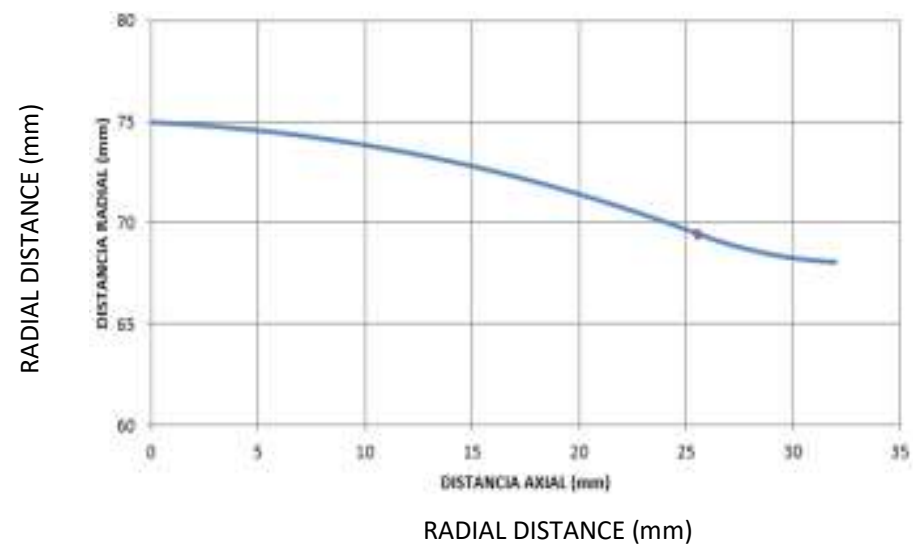

$\mathrm{R}_{1}=80 \mathrm{~mm} ; \mathrm{R}_{2}=19.8 \mathrm{~mm}$

Centre positions $(\mathrm{mm})$ :

$\mathrm{C}_{1}=(-4.0,-4.9) ; \mathrm{C}_{2}=(33.0,87.8)$

Figure 13. Roller profiles used in load transfer simulations at the double support phase
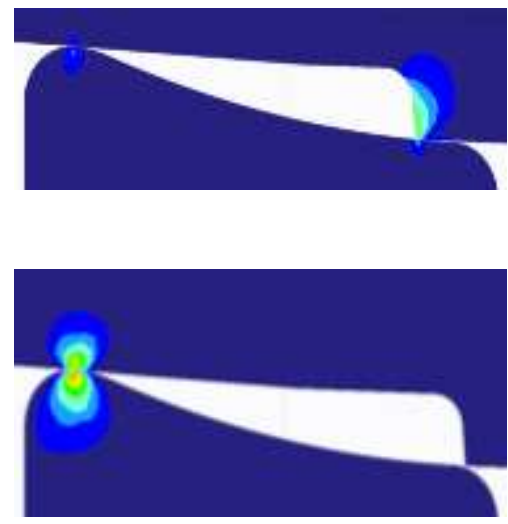

Figure 14. FEM graphs corresponding to the beginning (top) and end (bottom) of the double support phase 
In Figure 14 the beginning and the end of the double contact phase are shown for the first roller $\left(R_{1}=10 \mathrm{~mm}, R_{2}=95.1 \mathrm{~mm}\right)$, as obtained with a finite element software. Several static simulations have been performed between these two positions for each of the three profiles mentioned above.

The most relevant results of the simulations are condensed in the graphs of Figure 15. The green curves correspond to the roller with $\mathrm{R}_{1}=10 \mathrm{~mm}$; the curves in orange, to the roller with $\mathrm{R}_{1}=50 \mathrm{~mm}$; and the curves in red, to the roller with $\mathrm{R}_{1}=80 \mathrm{~mm}$. Solid lines are for (decreasing) contact forces at point $\mathrm{B}$, whereas dashed lines are for (increasing) contact forces at point A (for identification of points $\mathrm{A}$ and $\mathrm{B}$, see figures $2,5,7$ or 12 ).

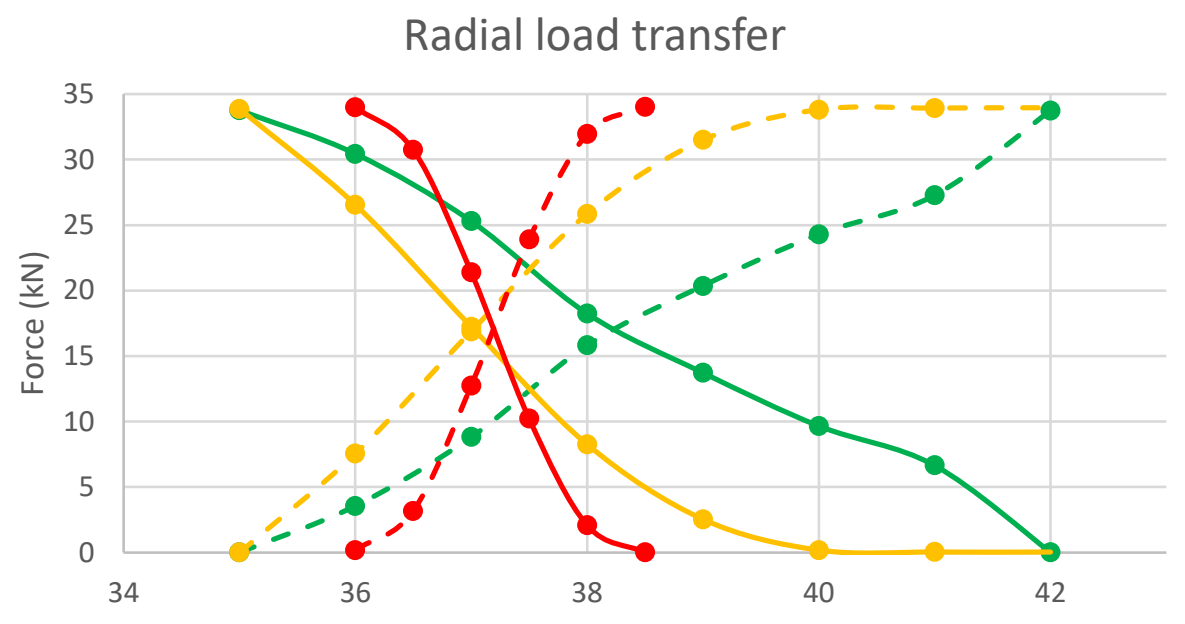

Axial tool progress $(\mathrm{mm})$

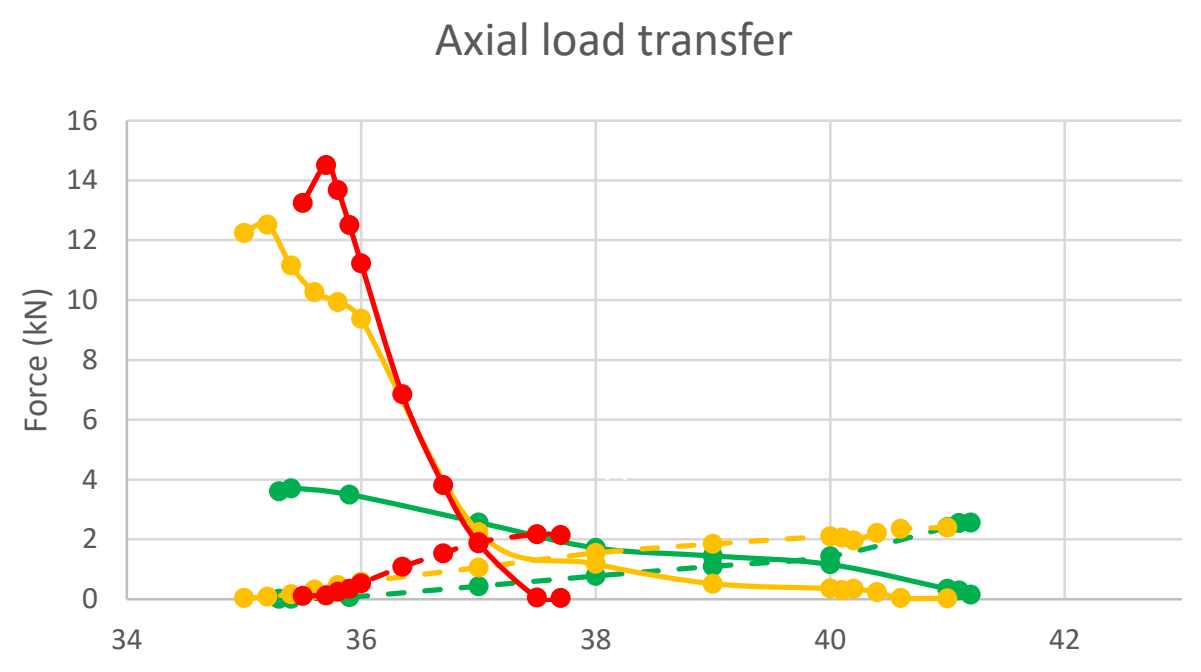

Axial tool progress $(\mathrm{mm})$

Figure 15. Radial and axial roller-wheel contact force transfer in the double-contact phase.

Green: $\mathbf{R}_{\mathbf{1}}=10 \mathrm{~mm}$; orange: $\mathbf{R}_{1}=50 \mathrm{~mm}$; Red: $\mathbf{R}_{\mathbf{1}}=80 \mathrm{~mm}$.

Dashed line: contact force in the convex zone of the roller (point A). Solid line: contact force between the machining edge and the concave zone of the roller (point B). 
In view of these graphs, the conclusion is that the roller which concave section has greater radius is the one that produces a smoother, radial and axial load transfer. In general, the lower slope of the roller at point $\mathrm{B}$, the smoother the load transfer will occur from support at point B to support at point A. This is achieved for small values of $R_{1}$, but this radius cannot be arbitrarily small, since the contact pressure increases as it decreases. With a value of $R_{1}=10 \mathrm{~mm}$, a Von Mises stress less than $4500 \mathrm{MPa}$ has been obtained, which we consider a fairly acceptable value.

\section{Conclusions}

In this article, a problem associated with wheel re-profiling process by under-floor lathes with a single cutting tool is first discussed. With these lathes an abrupt axial load transfer occurs when re-profiling, which is related with the profile geometry of the current support rollers used in the process.

Then, a new kind of support roller profile has been presented as a solution of the problem, being the concave-convex geometry its main feature. The methodology to design the parametrized optimum roller profile is developed and verified.

The verifications have been made by finite element static analysis along the process, made for three profiles with different values of their concave-convex curvature radii. The results are presented in section 4, where it is shown that the greater the radius of curvature of the concave section (or less that of the convex, the sum of both being fixed), the lower the load transfer in the double support. However, the radius of curvature of the convex section cannot be arbitrarily small, as it would lead to arbitrarily large values of the contact pressure, right where the roller supports most of the reprofiling process. For a roller $75 \mathrm{~mm}$ radius, its convex section radius of curvature of $10 \mathrm{~mm}$ is large enough to support a common wheel during its reprofiling process with existing lathes.

The rollers with the new profile have been implemented in an under-floor lathe showing good results.

\section{Declarations}

The authors declare that they have no known competing financial interests or personal relationships that could have appeared to influence the work reported in this paper.

\section{Funding}

Not applicable

\section{Ethical approval}

No part of this study was performed on any human or animal subjects.

\section{Consent to participate}

Not applicable.

\section{Consent for publication}

Not applicable.

\section{Conflict of Interest}

The authors declare that they have no conflict of interest 


\section{Contributions}

All the authors designed research, performed research, analyzed data, and wrote the paper.

\section{Acknowledgement}

This work was financially supported by the Spanish Government through the MCYT project 395 "RETOS2015: sistema de monitorización integral de conjuntos mecánicos críticos para la mejora del mantenimiento en el transporte-maqstatus."

\section{References}

[ 1] M.J. Gómez, C. Castejón, E. Corral, J.C. García-Prada. Analysis of the influence of crack location for diagnosis in rotating shafts based on 3 x energy. Mechanism and Machine Theory. Volume 103, 2016, Pages 167-173,ISSN 0094-114X, https://doi.org/10.1016/j.mechmachtheory.2016.05.006.

[ 2] Gómez, M.J.; Corral, E.; Castejón, C.; García-Prada, J.C. Effective Crack Detection in Railway Axles Using Vibration Signals and WPT Energy. Sensors 2018, 18, 1603.

[ 3 ]Gómez, M.J.; Castejón, C.; Corral, E.; García-Prada, J.C. Railway Axle Condition Monitoring Technique Based on Wavelet Packet Transform Features and Support Vector Machines. Sensors 2020, 20, 3575.

[ 4] Li, Y.F.; Liu, J.X.;Wang, Y. Railway Wheel Flat Detection Based on Improved Empirical Mode Decomposition. Shock Vib. 2016, 2016. [CrossRef]

[ 5] Ling, L.; Cao, Y.B.; Xiao, X.B.; Wen, Z.F.; Jin, X.S. Efect of Wheel Flats on the High-speed Wheel-Rail Contact Behavior. J. China Railw. Soc. 2015, 37, 32-39.

[ 6] Bogdevicius, M.; Zygiene, R.; Subacius, R. Employment of Two New Methods for the Research of Interaction of Wheel with a Flat and Rail. Solid State Phenom. 2017, 260, 289-294. [CrossRef]

[ 7] Uzzal, R.U.A.; Ahmed, W.; Bhat, R.B. Impact analysis due to multiple wheel flats in three-dimensional railway vehicletrack system model and development of a smart wheelset. Proc. Inst. Mech. Eng. Part F J. Rail Rapid Transit 2016, 230, 450-471. [CrossRef]

[ 8] Yang, J.; Thompson, D.J.; Takano, Y. Characterizing Wheel Flat Impact Noise with an E_cient Time Domain Model. Notes Numer. Fluid Mech. Multidiscip. Des. 2015, 126, 109-116.

[ 9] Bogdevicius, M.; Zygiene, R.; Bureika, G.; Dailydka, S. An analytical mathematical method for calculation of the dynamic wheel-rail impact force caused by wheel flat. Veh. Syst. Dyn. 2016, 54, 689-705. [CrossRef]

[ 10] Kaewunruen, S.; Remennikov, A.M. Impact responses of prestressing tendons in railway concrete sleepers in high speed rail environments. In Proceedings of the 5th International Conference on Computational Methods in Structural Dynamics and Earthquake Engineering, Crete Island, Greece, 25-27 May 2015.

[ 11] Zhang, Z.; Wei, S.; Andrawes, B.; Kuchma, D.A.; Edwards, J.R. Numerical and experimental study on dynamic behaviour of concrete sleeper track caused by wheel flat. Int. J. Rail Transp. 2016, 4, 1-19.

[12] G. W. Yang, Y. J. Wei, G. L. Zhao et al., "Current research progress in the mechanics of high speed rails," Advances in Mechanics, vol. 45, pp. 217-460, 2015.

[13] F. Braghin, S. Bruni, and F. Resta, "Wear of railway wheel profiles: A comparison between experimental results and a mathematical model," Vehicle System Dynamics, vol. 37,pp. 478-489, 2003.

[14] W. J. Ren, D. B. Cui, L. Li, and J. Su, "Influence of wheel reprofiling on wheel-rail profile matching performance," Lubrication Engineering, vol. 40, no. 5, pp. 16-21, 2015.

[ 15] M.H El-Axir. An investigation into roller burnishing. International Journal of Machine Tools and Manufacture, Volume 40, Issue 11, 2000, Pages 1603-1617, ISSN 0890-6955, https://doi.org/10.1016/S0890-6955(00)00019-5. 
[ 16] Pascale Balland, Laurent Tabourot, Fabien Degre, Vincent Moreau, An investigation of the mechanics of roller burnishing through finite element simulation and experiments, International Journal of Machine Tools and Manufacture, Volume 65, 2013, Pages 29-36, ISSN 0890-6955, https://doi.org/10.1016/j.ijmachtools.2012.09.002.

[17] Koji Utsumi, Shoki Shichiri, Hiroyuki Sasahara, Determining the effect of tool posture on cutting force in a turn milling process using an analytical prediction model, International Journal of Machine Tools and Manufacture, Volume 150, 2020, 103511, ISSN 0890-6955, https://doi.org/10.1016/j.ijmachtools.2019.103511.

[ 18] Bugra Kilic, Juan A. Aguirre-Cruz, Shivakumar Raman, Inspection of the cylindrical surface feature after turning using coordinate metrology, International Journal of Machine Tools and Manufacture, Volume 47, Issues 12-13, 2007, Pages 1893-1903, ISSN 0890-6955, https://doi.org/10.1016/j.ijmachtools.2007.03.007.

[ 19] Ding, WF, Dai, CW , Yu, TY , Xu, JH , Fu, YC . Grinding performance of textured monolayer CBN wheels: Undeformed chip thickness nonuniformity modeling and ground surface topography prediction International Journal of Machine Tools and Manufacture, Volume122 Páginas: 52-66. DOI: 10.1016/j.ijmachtools.2017.05.006

[ 20] Hoon Huh, Jin Hyuck Heo, Hyoung Wook Lee. Optimization of a roller levelling process for Al7001T9 pipes with finite element analysis and Taguchi method, International Journal of Machine Tools and Manufacture, Volume 43, Issue 4, 2003, Pages 345-350, ISSN 0890-6955, https://doi.org/10.1016/S0890-6955(02)00269-9.

[ 21] Yanglin Peng, Yifan Dai, Ci Song, Feng Shi, Tool deflection model and profile error control in helix path contour grinding, International Journal of Machine Tools and Manufacture, Volume 111, 2016, Pages 1-8, ISSN 0890-6955, https://doi.org/10.1016/j.ijmachtools.2016.08.005.

[ 22] Simmons Machine Tool Corporation. Available at: http://smtgroup.com/products/underfloortechnology/underfloorwheel-truing-machine-stanray.

[ 23] B. Zhang, Z. Lu, and C. Tang, "Wheel reprofiling of high-speed EMU based on multi-objective optimization strategy," Tongji Daxue Xuebao/Journal of Tongji University, vol. 41, no. 3, pp. 437-442, 2013.

[ 24] T. V. Chien, F. Li, Z. Qi, and J. J. Ding, "Processing method of locomotive wheel wear statistical data and prediction model of turning period," Tiedao Xuebao/Journal of the China Railway Society, vol. 37, no. 12, pp. 14-19, 2015.

[ 25] J. W. Seo, B. C. Goo, J. B. Choi, and Y. J. Kim, "Effects of metal removal and residual stress on the contact fatigue life of railway wheels," International Journal of Fatigue, vol. 30, no. 10-11, pp. 2021-2029, 2008.

[ 26] K. Filipowicz, W. Biedunkiewicz, M. Krolikowski, and D. Grzesiak, "Machining of resilient wheelsets on wheel-turning lathes," in DAAAM International Scientific Book 2010, 2010.

[ 27] Z. Tian, "Economic selection of milling cutters for wheel tread reprofiling ofCRH2 type EMU," ChinaHigh-tech Enterprise, vol.no.18, pp. 102-103, 2014.

[ 28] D. Cioboata, A. Abalaru, D. Stanciu, L. Cristian, I. Ghionea, and S. Szekely, "Technological system for profiling/reprofiling railway wheel sets," Optics \& Mechatronics, no. 47, pp. 79-85, 2015.

[ 29] A. R. Andrade and J. Stow, "Assessing the efficiency of maintenance operators: a case study of turning railway wheelsets on an under-floor wheel lathe," Proceedings of the Institution of Mechanical Engineers, Part O: Journal of Risk and Reliability, vol. 231, no. 2, pp. 155-163, 2017. 
Figures
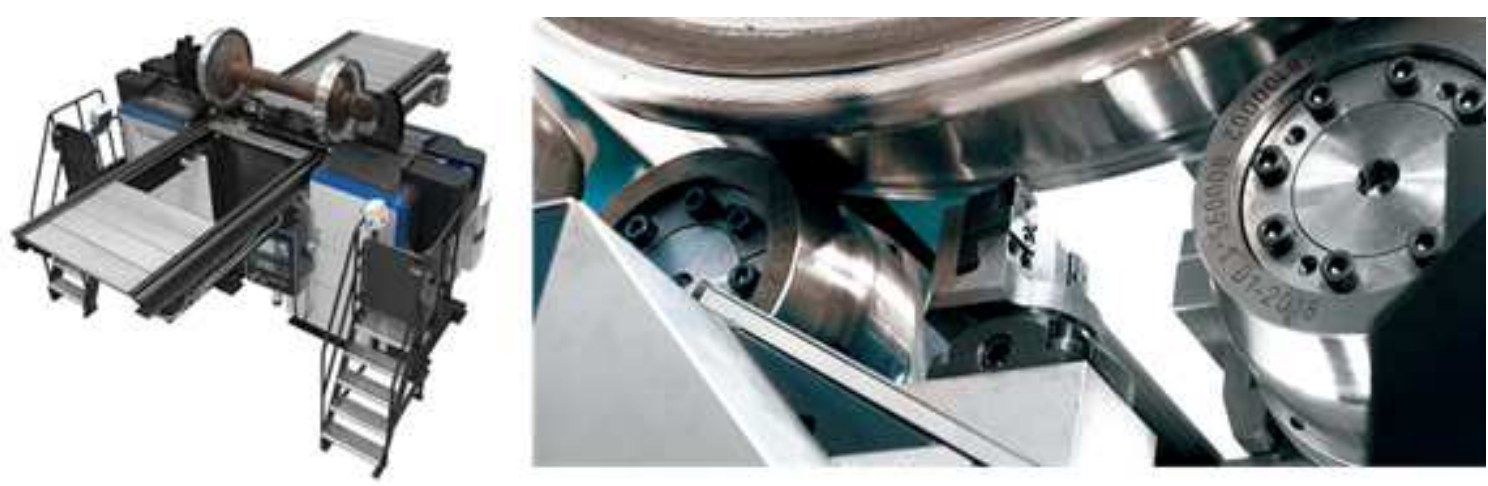

Figure 1

Single tool underfloor wheel lathe for railway wheel re-profiling

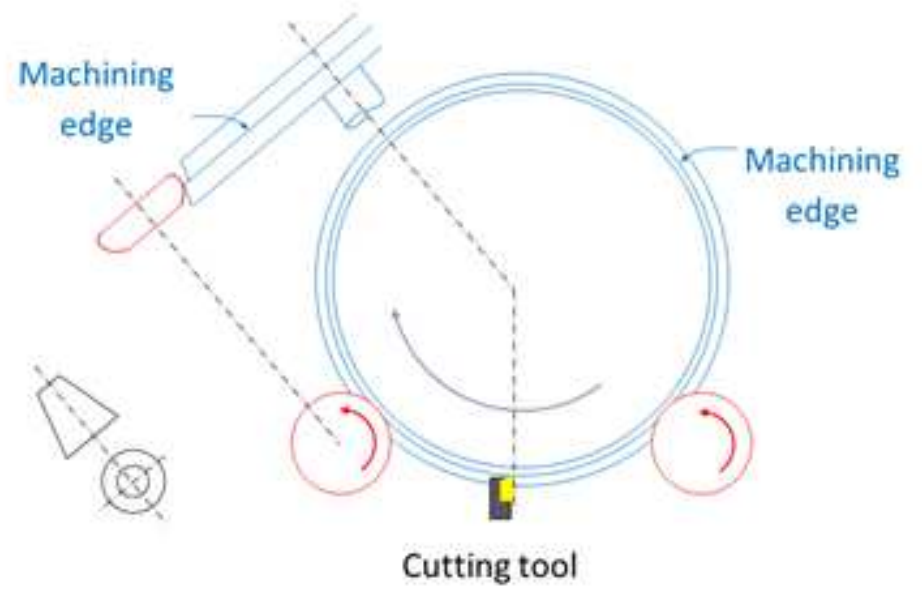

Figure 2

Front and side views showing the configuration of the support rollers (red), the cutting tool (yellow) and the wheel to be re-profiled (blue). The machining edge during the re-profiling process is also shown 


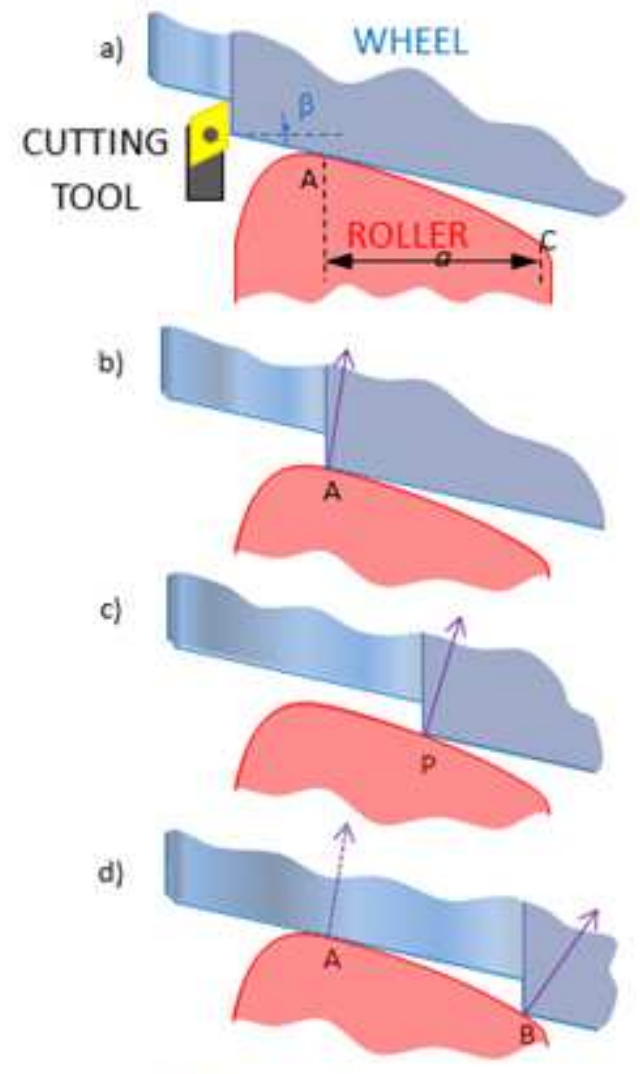

e)

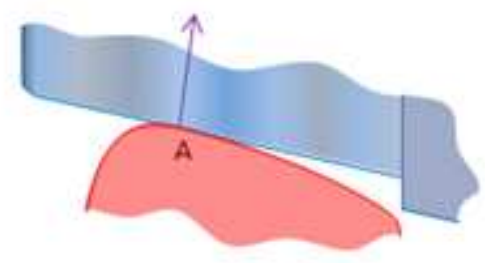

\section{Figure 3}

Cross section of roller and wheel at different re-profiling phases (the cutting tool drawn in a) is out of section)

a)

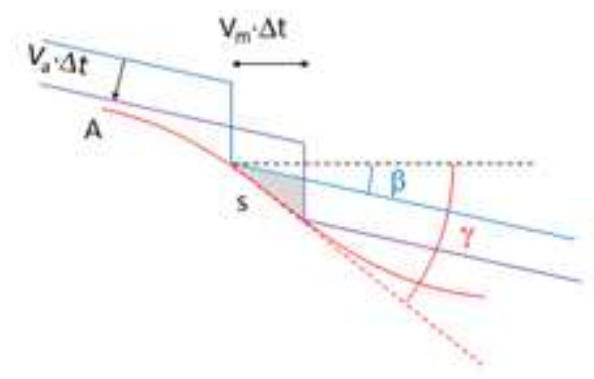

b)

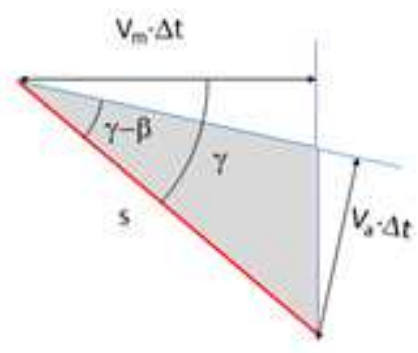

\section{Figure 4}

a) Two succesive positions (separated by the time Interval $\square t$ ) of the wheel being re-profiling (in blue and purple, respectively) supported on the roller (in red). b) detail of the shaded area showing the involved 


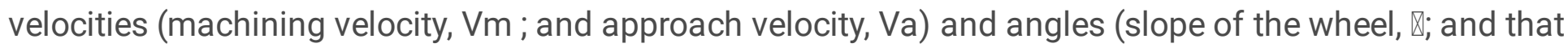
of the roller profile at the contact, $\mathbb{\bigotimes})$.
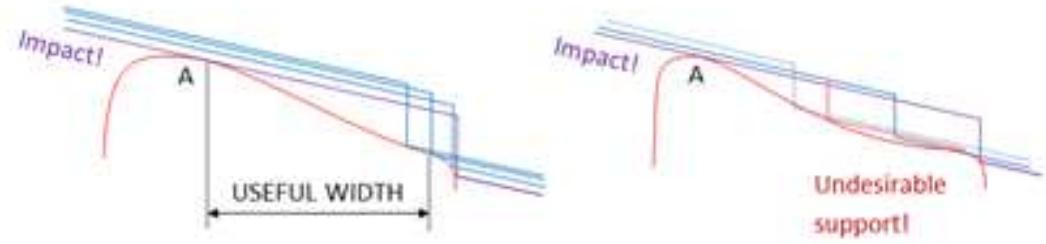

\section{Figure 5}

Situations that lead to a second impulsive support of the wheel in the re-profiling process: i) the reprofiling edge leaves the area of useful width prematurely (left); ii) there is prior undesirable support (right).

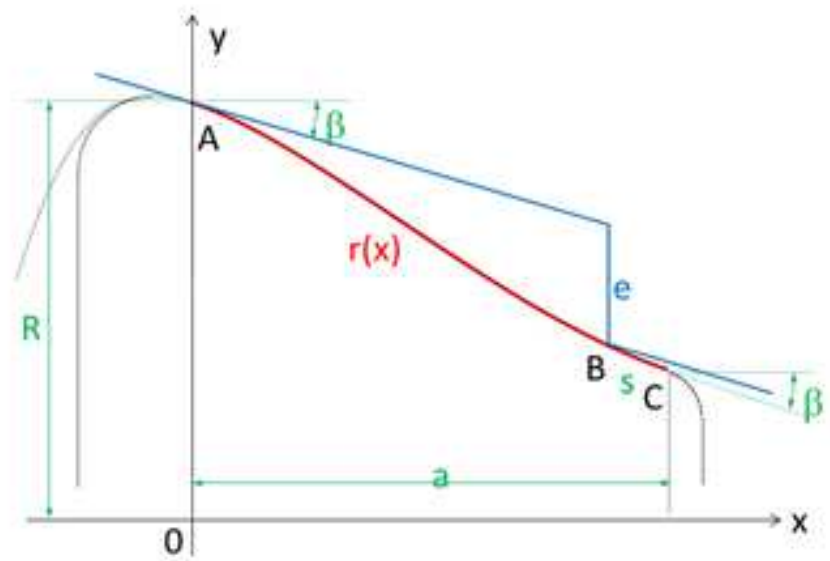

\section{Figure 6}

Roller profile according to constraints. Wheel profile in the double support phase of the re-profiling process. Design parameters: $b, a, R, e, s$

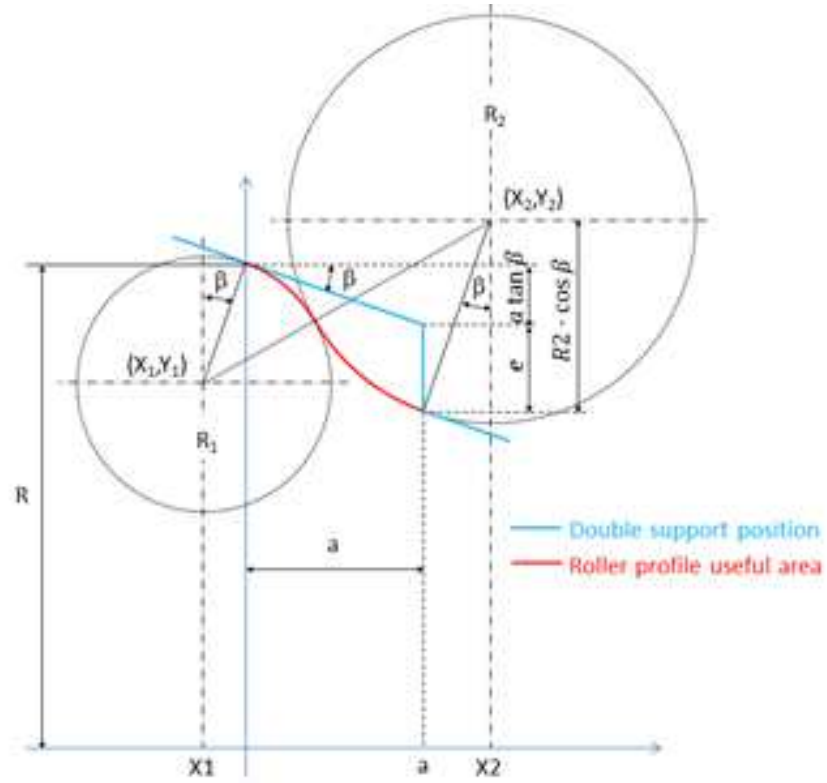


Figure 7

Roller profile composed of two circumference sections. Positions of the circumference centres and radios. First approach design without considering safety distance.

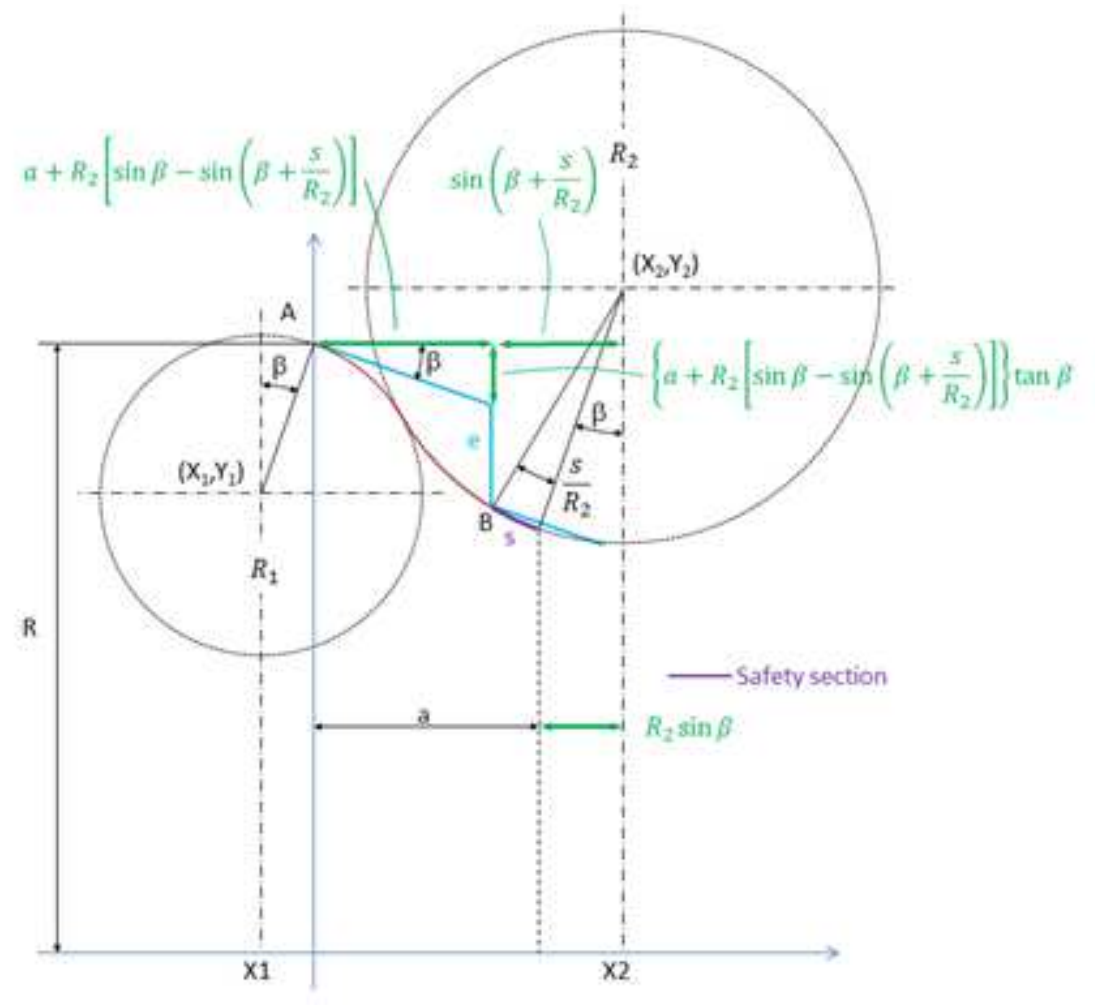

\section{Figure 8}

Design parameters of the roller composed of two circumference arcs, considering a safety distance, s.
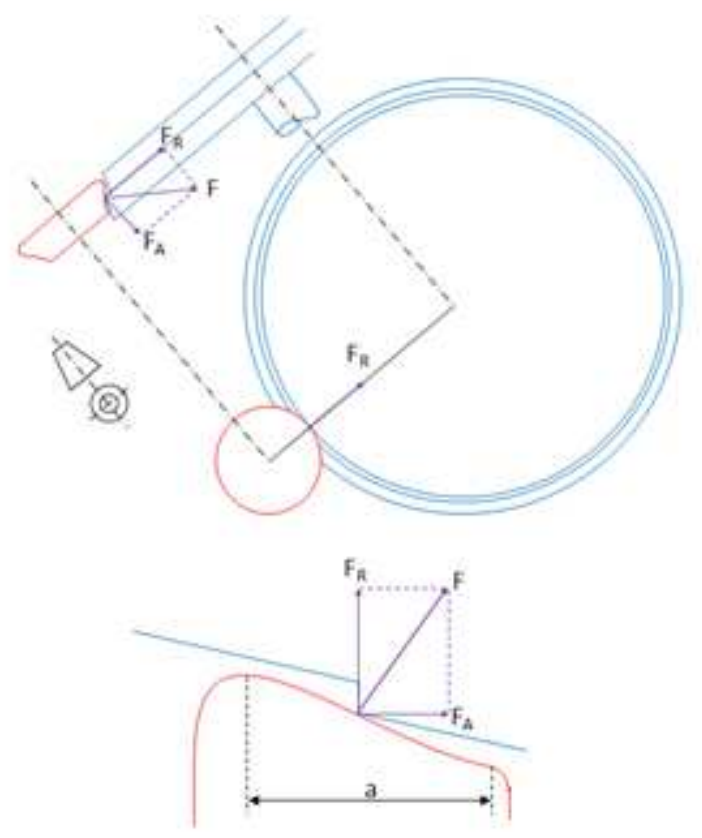

Figure 9 
Roller-wheel contact force decomposition into radial and axial components

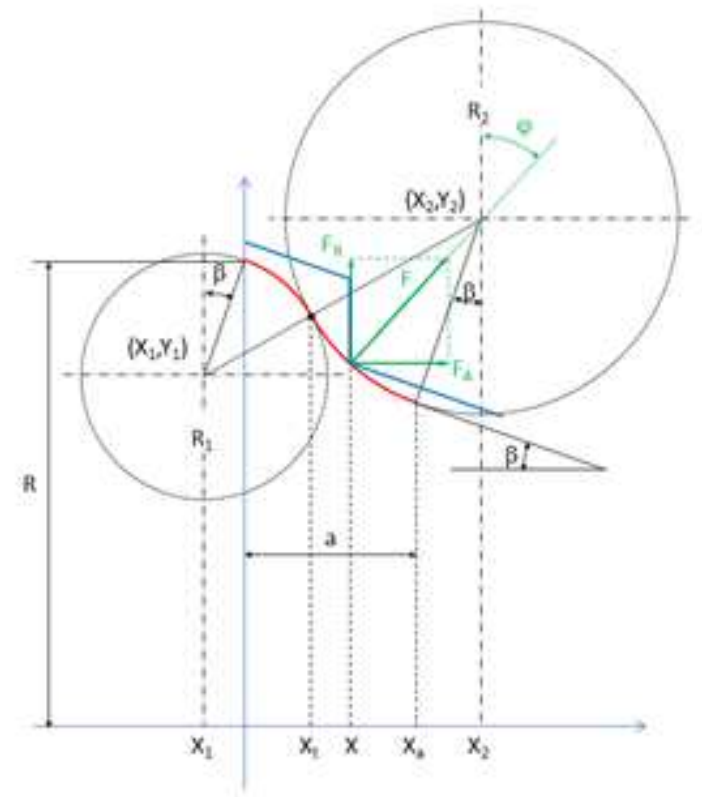

\section{Figure 10}

Roller-wheel contact force. Axial and radial components

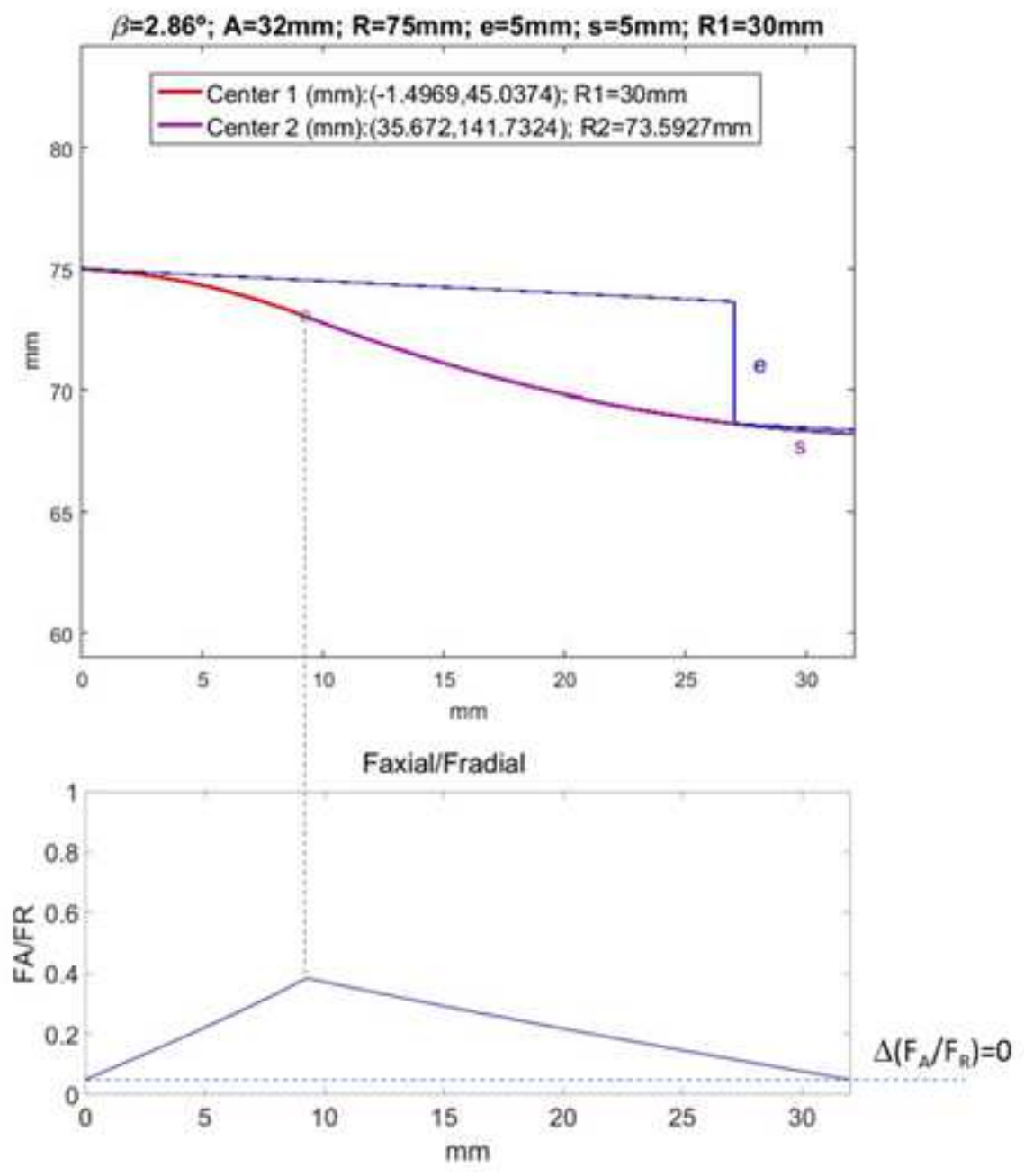




\section{Figure 11}

Top: optimal roller profile for the indicated design parameters. Bottom: ratio between the axial and radial components of the contact force, throughout the re-profiling process. the axial component grows to a maximum just at the inflection point of the profile. From that point on, it decreases to the same value as in the first support. As a consequence, there is no axial load transfer.
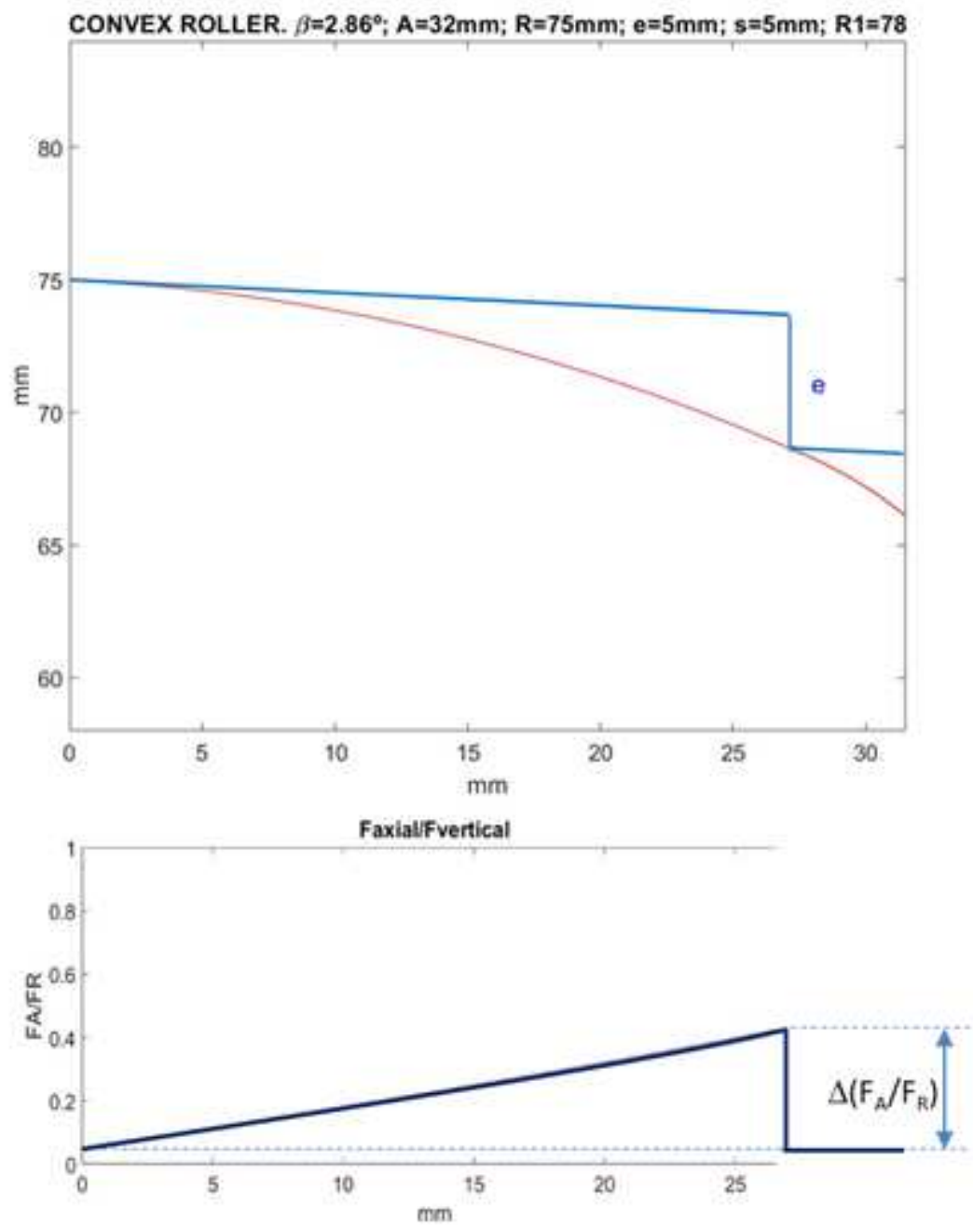

\section{Figure 12}

Top: Convex roller profile for the indicated design parameters. Bottom: ratio between the axial and radial components of the contact force, throughout the re-profiling process. In this case, an abrupt load transfer occurs in the second support. 


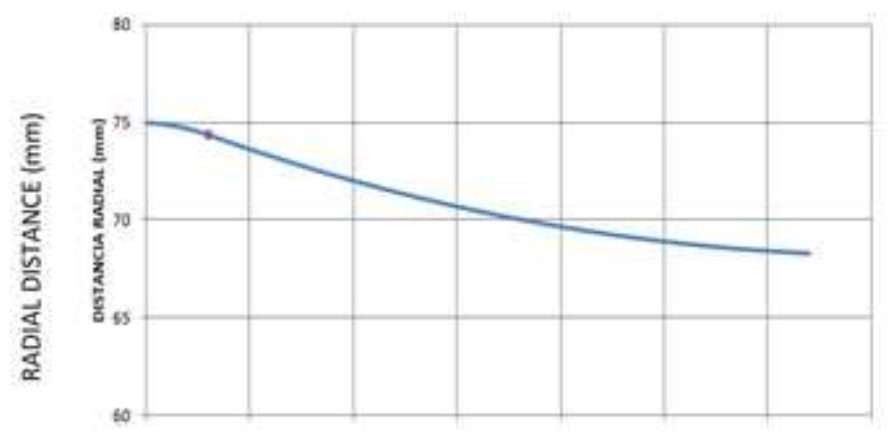

$\mathrm{R}_{1}=10 \mathrm{~mm} ; \mathrm{R}_{2}=95.1 \mathrm{~mm}$

Centre positions ( $\mathrm{mm})$ :

$C_{1}=(-0.5,65.0) ; C_{2}=(36.7,163.3)$

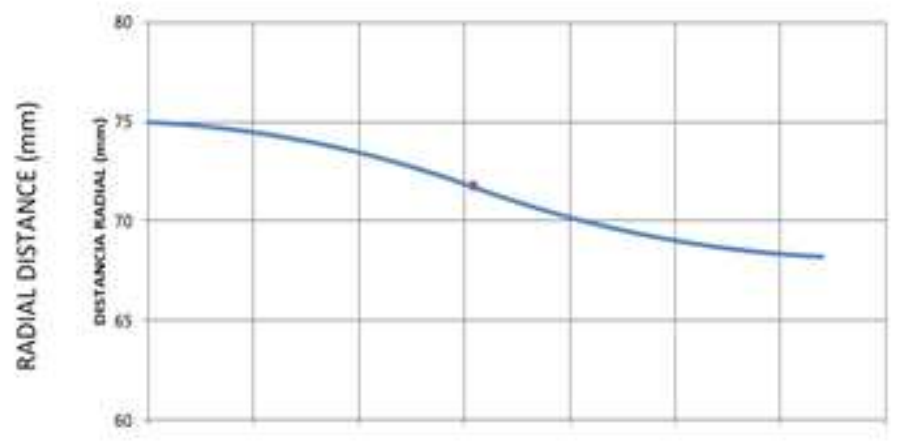

$R_{1}=50 \mathrm{~mm} ; R_{2}=53.9 \mathrm{~mm}$

Centre positions $(\mathrm{mm})$ :

$\mathrm{C}_{1}=(-2.5,25.1) ; \mathrm{C}_{2}=(34.7,122.1)$

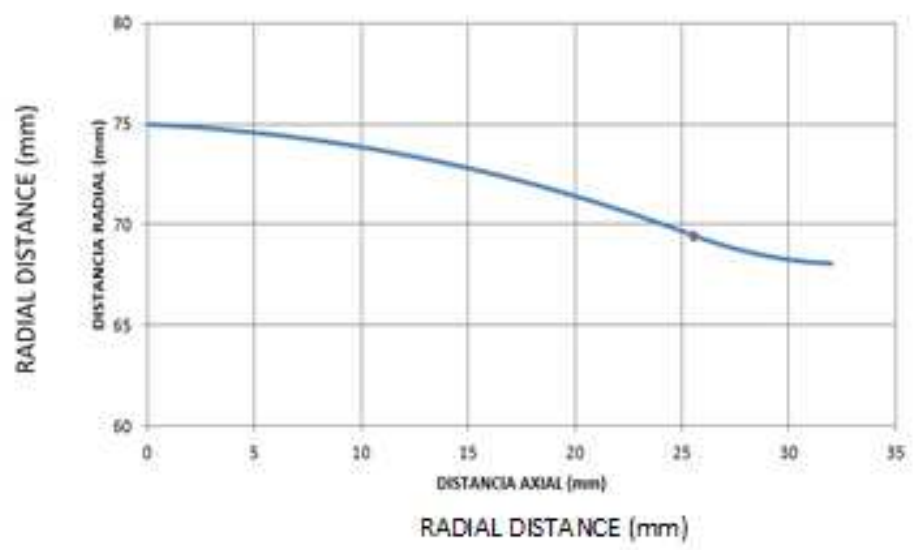

$R_{1}=80 \mathrm{~mm} ; R_{2}=19.8 \mathrm{~mm}$

Centre positions $(\mathrm{mm})$ :

$\mathrm{C}_{1}=(-4.0,-4.9) ; \mathrm{C}_{2}=(33.0,87.8)$

\section{Figure 13}

Roller profiles used in load transfer simulations at the double support phase
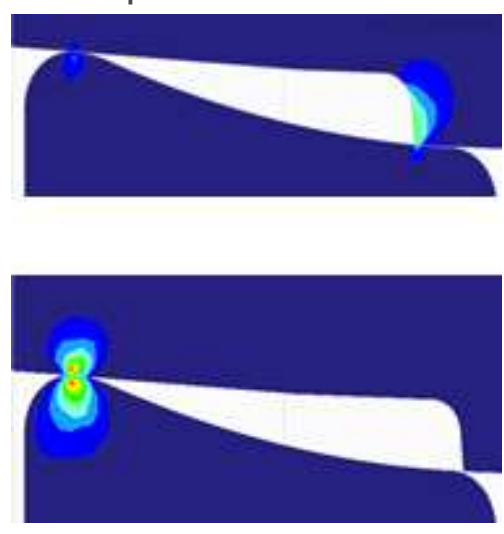

Figure 14

FEM graphs corresponding to the beginning (top) and end (bottom) of the double support phase 


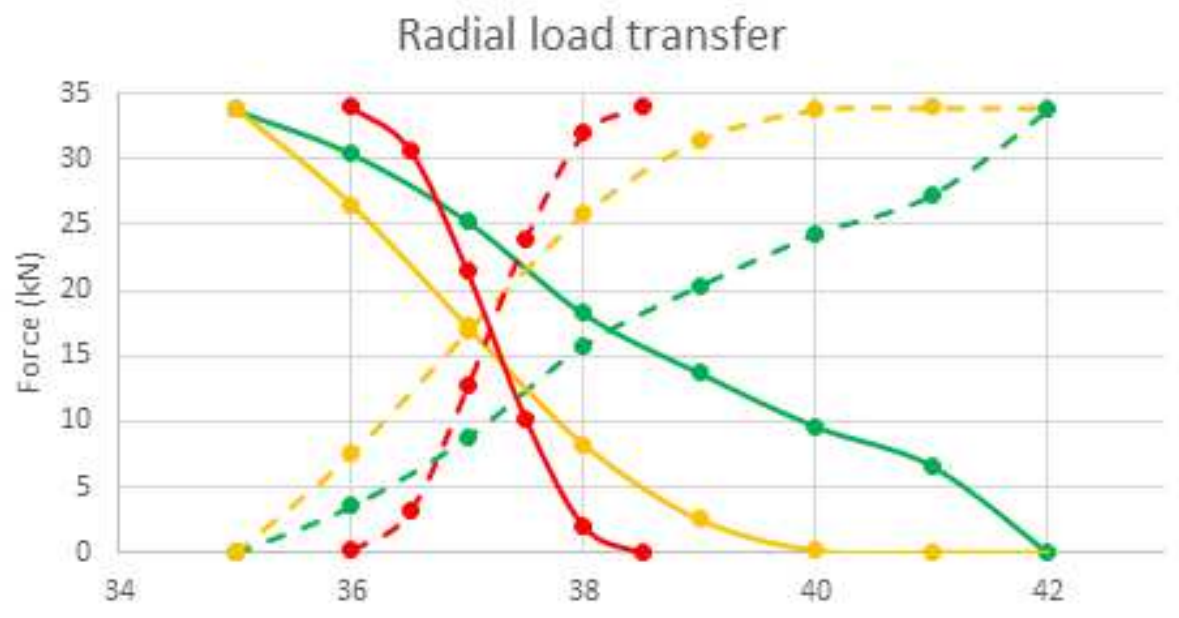

Axial tool progress (mm)

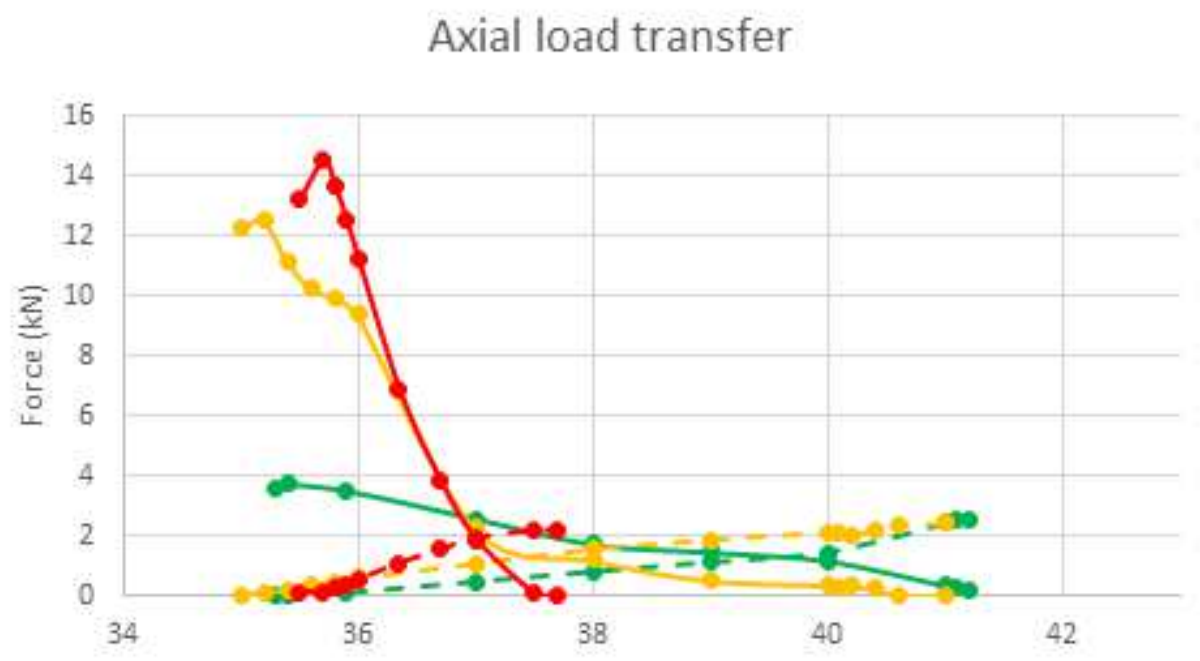

Axial tool progress (mm)

Figure 15

Radial and axial roller-wheel contact force transfer in the double-contact phase. Green: R1 $=10 \mathrm{~mm}$; orange: R1 $=50 \mathrm{~mm}$; Red: R1 $=80 \mathrm{~mm}$. Dashed line: contact force in the convex zone of the roller (point A). Solid line: contact force between the machining edge and the concave zone of the roller (point B). 